\title{
El horno protohistórico de reducción directa de La Pastora (Aliseda, Cáceres)*
}

\author{
The protohistoric bloomery furnace of La Pastora (Aliseda, Cáceres)
}

\author{
Ignacio Pavón Soldevila ${ }^{a}$, David M. Duque Espino ${ }^{a}$, Martina Renzi ${ }^{b}$, Salvador Rovira \\ Lloréns $^{c}$ y Alonso Rodríguez Díaz
}

\begin{abstract}
RESUMEN
El presente estudio da a conocer los restos de un horno protohistórico empleado para la reducción de mineral de hierro recientemente documentado en la mina La Pastora (Aliseda, Cáceres). Este yacimiento es especialmente importante también por haber proporcionado los primeros fragmentos de escorias de sangrado conocidos en Iberia. A partir de la información recuperada en su contexto, se plantean propuestas sobre su tipología y el proceso minero-metalúrgico llevado a cabo, incidiendo en la caracterización del mineral, el combustible, el producto final, las escorias y la escala de la producción. Finalmente, se trata de contextualizar el caso de La Pastora en el marco de los estudios sobre hornos de reducción directa de la Península Ibérica.
\end{abstract}

\begin{abstract}
This paper focuses on the study of the remains of a Protohistoric furnace used for iron smelting that has been recently excavated at La Pastora mine (Aliseda, Cáceres). This site is particularly important also because it yielded the first fragments of tap slag known so far in Iberia. Thanks to the information extrapolated from its context, we examine the typology of the furnace and the mining-metallurgical process carried out there, with special emphasis on the characterisation of the ore, fuel, the final product, the slag and the scale of production. Finally, we
\end{abstract}

contextualize the case of La Pastora in the framework of studies of bloomery furnaces in the Iberian Peninsula.

Palabras clave: Edad del Hierro; Extremadura; Hierro; Metalurgia; Hornos de reducción directa; Escorias.

Key words: Iron Age; Extremadura; Iron; Metallurgy; Bloomery furnaces; Slags.

\section{INTRODUCCIÓN}

La aparición de la metalurgia del hierro constituye un problema histórico apasionante, se analice a escala mundial o estrictamente de la Península Ibérica, pues en ambas es un tema controvertido y aún abierto en sus múltiples vertientes. En nuestra geografía, si bien la presencia de objetos de hierro está atestiguada en contextos precoloniales (Almagro Gorbea 1993; Vilaça 2006, 2013), la generalización de los procesos de reducción del mineral de hierro en metal alienta una viva discusión contextualizada esencialmente en la Primera Edad del Hierro. Encuadrándola en el sur y oeste peninsular, no hace mucho se exponía cómo las huellas primigenias de los procesos pirometalúrgicos relacionados con el hierro pueden observarse

* Este trabajo se inscribe en el Proyecto "El Tiempo del Tesoro de Aliseda" (HAR2010-14917) y Acción Complementaria "Estudio del contexto arqueológico del Tesoro de Aliseda (Cáceres)" (HAR2011-15841-E), Plan Nacional I+D+i del MICINN-MINECO.

a Área de Prehistoria. Facultad de Filosofía y Letras. Universidad de Extremadura. Campus Universitario s/n. 10005 Cáceres. Correos e.: ipavon@unex.es orcid.org/0000-0002-6130-6463; despino@unex.es orcid.org/0000-0002-6045-3031; alonso@unex.es orcid.org/0000-0002-4602-4337.

b University College London Qatar (UCL Q). Georgetown building, Education City. PO BOX 25256. Doha. Qatar Correo e.: martina.renzi@ucl.ac.uk orcid.org/0000-0001-6466-9385.

c C/ Espartero 50-2 ${ }^{\circ}$ pta. 6. 46450 Benifaió. Valencia. Correo e.: s_rovirallorens@hotmail.com orcid.org/0000-0003-2463-0501.

Recibido 27-IX-2016; aceptado 11-I-2017. 
en varios centros fenicios fechados entre finales del siglo IX y comienzos del siglo VIII Cal BC (Rovira Lloréns y Renzi 2010: 87), si bien reparándose en la dificultad de vincularlas a prácticas de reducción directa (Renzi y Rovira Lloréns 2009; Renzi et al. 2013: 185). Como el grueso de las evidencias estudiadas en tales contextos fenicios y orientalizantes sugiere, parece constatarse una marcada dicotomía - evidentemente abierta a excepciones- entre los poblados o contextos habitados donde a lo sumo se han recuperado evidencias de post-reducción (Toscanos, Morro de Mezquitilla, Cerro del Villar o La Fonteta, entre otros) y otros exteriores habitualmente menos valorados desde la arqueología. En estos últimos, en teoría localizados en las proximidades de las zonas de extracción del mineral y captación del combustible, cabría encontrar a priori evidencias de las primeras fases del proceso productivo, siempre que la fortuna permitiese la conservación de estructuras por lo general muy efímeras.

En este sentido, no hace mucho presentábamos los resultados de un proyecto investigador en parte orientado a la valoración, mediante técnicas de prospección arqueominera, de una zona tradicionalmente distinguida en el discurso protohistórico por su riqueza metalífera, como es el actual territorio extremeño (Almagro Gorbea, 1977). Particularmente, incidíamos en su caracterización en el triángulo "Aliseda-Sierra de Fuentes-Casas de Don Antonio" (Cáceres), revisando para ello una serie de indicios de laboreo en la extracción de estaño, plata y hierro en 2011 (Rodríguez Díaz et al. 2013: 105-108). Restringiéndonos a este último recurso, y siguiendo los pasos de C. Domergue (1987: 52) que ya la había catalogado como "romana", valoramos la mina La Pastora (Aliseda, Cáceres) -en cuyo entorno pudieron advertirse y recogerse algunas escorias y escasas cerámicas- como el caso más elocuente de explotación antigua del hierro, justo en la vertiente opuesta al poblado protohistórico de la Sierra del Aljibe que venimos relacionando desde hace tiempo con el célebre Tesoro de Aliseda (Rodríguez Díaz y Pavón Soldevila 1999). Serán, precisamente, la presentación de los restos arqueológicos excavados recientemente en La Pastora y relacionados con la reducción directa del hierro, junto a la reconstrucción de los procesos metalúrgicos que ellos permiten, los objetivos específicos del presente estudio, integrados en una investigación más amplia en torno al tiempo del Tesoro de Aliseda (Rodríguez Díaz et al. 2014; Rodríguez Díaz et al. 2015).

\section{LA MINA LA PASTORA}

La mina La Pastora, que se sitúa a algo menos de $300 \mathrm{~m}$ al este de los crestones de la Sierra del Aljibe, es una buena muestra de las mineralizaciones de hierro estratoide en el Devónico del Sinclinal de Aliseda (Cáceres) (Rebollada Casado et al. 2010: 249) (Fig. 1). Geoquímicamente, su característica esencial es la ferruginización acusada de las cuarcitas y su paragénesis incluye oligisto, hematites, limonita, goethita y pirita. Sus óxidos e hidróxidos de hierro fueron puntualmente explotados a comienzos de los años veinte y de forma mucho más intensa en la década de los 1950 (Liberal Muñoz 2007: 10). La mena de hierro, una vez extraída, era directamente transportada en esos años a los Altos Hornos de Bilbao (Rebollada Casado et al. 2010: 250); es decir, no se reducía in situ, lo que alentaba la antigüedad de las escorias recuperadas en superficie en la mencionada prospección geominera de 2011. Como comprobamos en el curso de esos trabajos, tales evidencias no formaron verdaderos escoriales ni acumulaciones destacables en el relieve, pero sí pueden avistarse sobre el terreno a lo largo de una superficie estimada de unas 0,6 ha, que grosso modo delimita la presunta explotación antigua. Algo que, dicho sea de paso, no pasó desapercibido tampoco hace casi cien años a algunos de los pioneros en el estudio del Tesoro de Aliseda, como Miguel Ángel Ortí Belmonte (1921: 212, 1924: 88), quien ya advirtiera "la presencia de unas minas de hierro, que hemos visto, y cuyas escorias demuestran que han sido explotadas en la antigüedad". Estas escorias de superficie de La Pastora, específicamente de sangrado de horno, a la vista de los típicos cordones de derretido y de la analítica realizada sobre algunas muestras, guardan gran semejanza con las recuperadas en 1995 en el poblado de la Sierra del Aljibe, sito apenas $300 \mathrm{~m}$ a poniente (Rodríguez Díaz y Pavón Soldevila 1999). Dichas muestras, que ya fueron analizadas y valoradas hace unos años (Rovira Lloréns y Gómez Ramos 1999), proceden tanto de contextos estratigráficos de la Primera Edad del

Trab. Prehist., 74, N. ${ }^{\circ}$ 2, julio-diciembre 2017, pp. 335-354, ISSN: 0082-5638

doi: $10.3989 /$ tp.2017.12198 


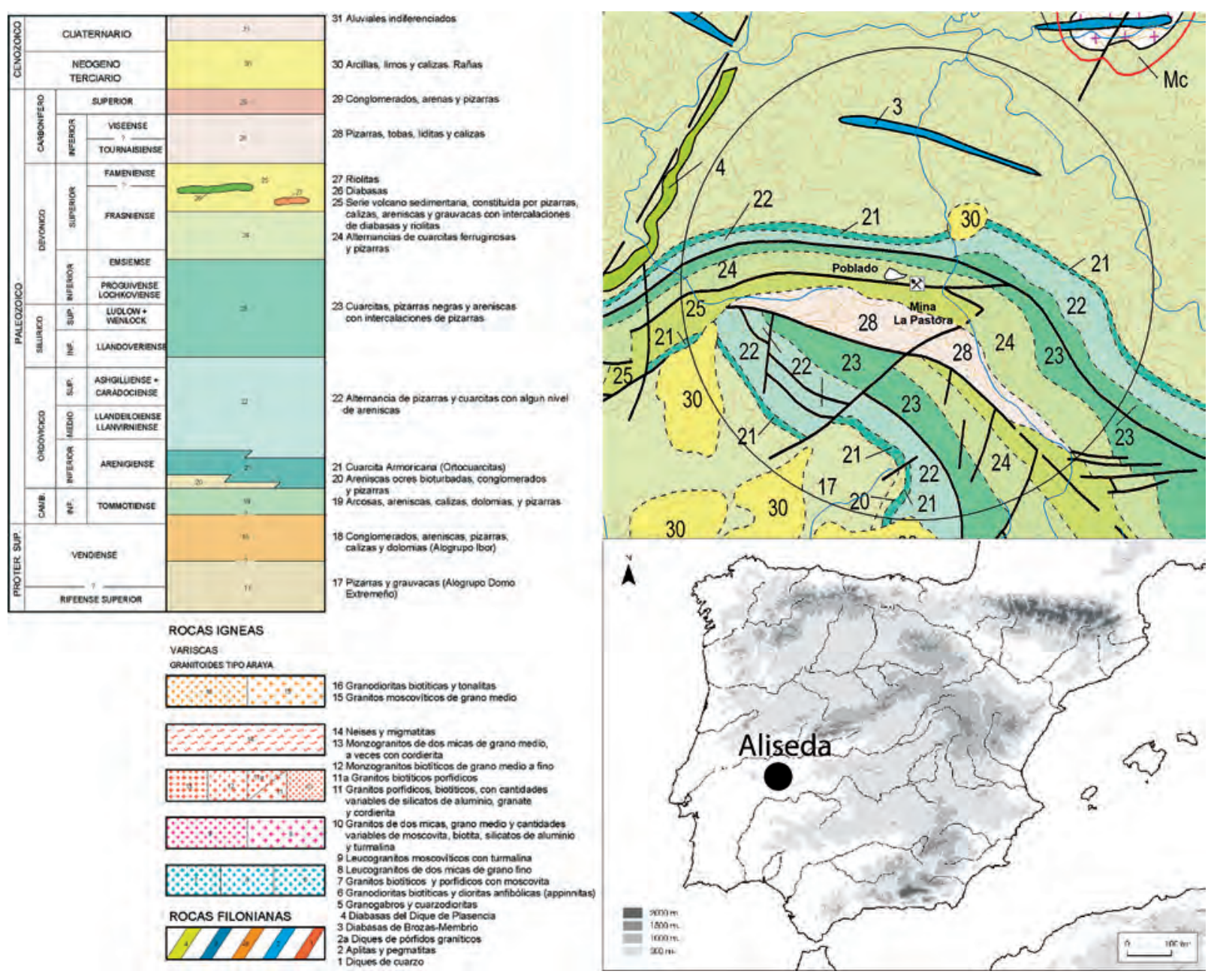

Fig. 1. Ubicación de la mina La Pastora (Aliseda, Cáceres) en el Mapa Geológico de Cáceres a escala 1:200.000 del Instituto Geológico y Minero de España (en color en la edición electrónica).

http://mapas.igme.es/gis/services/Cartografia_Geologica/IGME_GeologicoCaceres_200/MapServer/WMSServer?

Hierro como de los posteriores niveles romanorepublicanos. Por ello, teniendo en cuenta la tradicional adscripción -aún dominante- de las escorias de sangrado a la época romana como muy atrás (Gómez Ramos 1996: 151-153; Rovira Lloréns y Renzi 2010: 116; Gener Moret 2010: 214), nos situaron, pese al posible origen orientalizante de algunas de ellas, "ante una disyuntiva difícil de dilucidar" (Rovira Lloréns y Gómez Ramos 1999: 230-231), sembrando ciertas dudas sobre la cronología de la siderometalurgia en Aliseda.

Precisamente con la intención de disipar tales interrogantes $\mathrm{y}$, sobre todo, de ampliar el conocimiento sobre la minería antigua del hierro en el Tajo Medio, planteamos y acometimos en el verano de 2014 una excavación arqueológica en el entorno de La Pastora. Las expectativas, en principio, no eran muchas por el temor a la más que probable destrucción de contextos antiguos por causa del laboreo contemporáneo; pero a la postre, y por los argumentos que en seguida se expondrán, ha motivado el presente estudio. Los trabajos de excavación se desarrollaron dentro de un espacio que hoy permanece cercado, musealizado y es visitable en la referida mina, concretamente entre los niveles 2 y 3 señalados en el "itinerario minero" abierto al público (Rebollada Casado et al. 2010: 253-254). Consistieron en la apertura de seis calicatas de sondeo de dimensiones variables, aunque reducidas, distribuidas a 
diferentes cotas sobre las terrazas que jalonan la ruta de visita. Se trató de favorecer así un planteamiento estratigráfico acorde con el primero de los objetivos planteados, aunque susceptible en caso positivo de transformarse en extensivo. En relación con ello, cabe apuntar que, salvo el Corte 3 , los demás solo depararon algunos restos cerámicos (con fragmentos a mano, a torno toscos, oxidantes lisos y grises; junto a algunas pastas comunes modernas), y escorias de sangrado en proporciones variables sobre las que en su momento volveremos.

\section{EL ABRIGO-TALLER SIDERÚRGICO DE ÉPOCA PROTOHISTÓRICA}

\subsection{El horno de reducción}

Como ya se indicara en una publicación anterior, la información más completa sobre la arqueología minero-metalúrgica de Aliseda se ha obtenido en el Corte 3 (Pavón Soldevila et al. 2015), ubicado en un espacio aterrazado y protegido por un gran afloramiento cuarcítico, verdadero abrigo que lo resguarda de los vientos y precipitaciones suroccidentales dominantes (Fig. 2) ${ }^{1}$. Esta circunstancia, que de hecho ha motivado su frecuentación hasta casi nuestros días (atestiguada por restos de fogatas y residuos modernos visibles en superficie y extensibles a la unidad estratigráfica superficial), muy posiblemente también ayude a explicar la documentación arqueológica allí registrada.

El espacio intervenido inicialmente se limitó a una cata de 2 por $2 \mathrm{~m}$, pero el descubrimiento de estructuras pirometalúrgicas motivó sucesivas ampliaciones hasta alcanzar finalmente unos 15 $\mathrm{m}^{2}$. Pese a ello, estratigráficamente su lectura no es compleja. Se constató como sedimento más reciente la ya aludida unidad superficial de tierra vegetal y cenizas más o menos recientes $(\mathrm{UE} 300=305)$. Esta, en parte, descansaba sobre una posible estructura de mampuestos desbaratada y prácticamente irreconocible, sobre la que

${ }^{1}$ Las figs. 2-7 y 9-11 reproducen total o parcialmente las publicadas por los autores en Rodríguez et al. (2015: 125, 128, 130-132, 344, 346-347 y 351). apoyaba lateralmente un fragmento de molino de vaivén de gran tamaño (UE301) de clara tipología pre- o protohistórica. Ambas unidades se
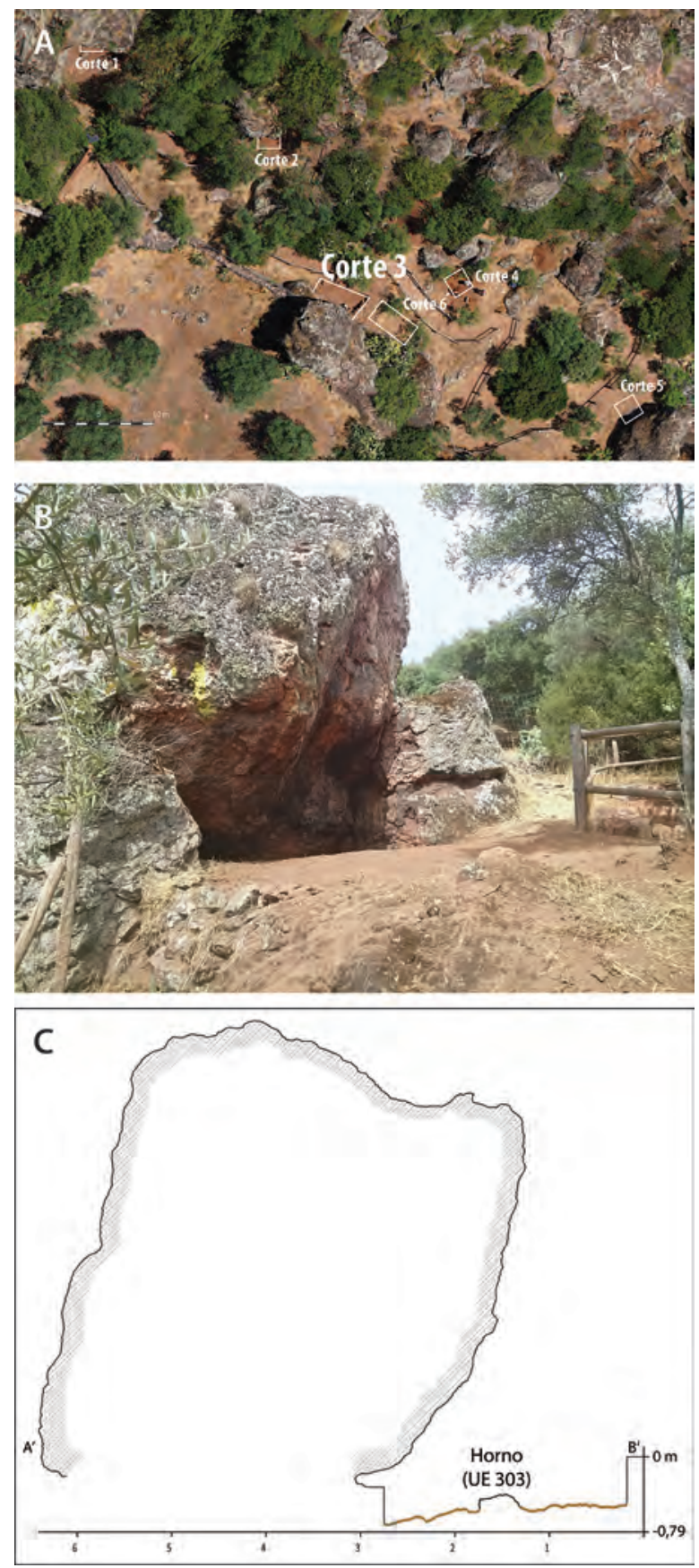

Fig. 2. Mina La Pastora: A. Distribución de los sondeos (2014); B. Abrigo en el que se planteó el Corte 3; C. Sección noroeste-sureste del abrigo y del Corte 3 (en color en la edición electrónica). 
superponían a su vez a un estrato menos suelto que el primero, de tonalidad anaranjada y con piedrecillas de pequeño tamaño (UE 302), que cabe interpretar como el nivel de abandono de las estructuras relacionadas con la reducción del hierro. Estas (identificadas como UEs 303 y 307) descansaban sobre una superficie de uso, pues no se trata estrictamente de un suelo preparado, formada por piedrecillas, ligeramente en pendiente y contenida por un afloramiento de cuarcita, a cuya cota interrumpimos la excavación. Sin embargo, en un sondeo practicado en ese mismo Corte 3 , al suroeste del coronamiento de dicho afloramiento, se detectaron sucesivamente otras dos unidades estratigráficas más compactas bajo dicha cota, caracterizadas respectivamente por sus tonalidades anaranjadas y rojizas y, en el caso de la última, abundante cascajo no lejos de la roca base. Ambas (denominadas UEs 304 y 306) resultaron arqueológicamente estériles (Fig. 3).

Pero son las unidades estratigráficas 303 y 307 las de mayor interés. La primera se corresponde con los restos in situ, con un color gris blanquecino muy característico, de parte de una estruc- tura de reducción para el beneficio del hierro, identificable con el cuerpo -cubeta o campana, si seguimos la terminología empleada por Gallego Cañamero (2013: 350, Fig. 1)- de un horno que conserva en alzado apenas unos $0,25 \mathrm{~m}$ (Figs. 4 y $5 \mathrm{~A}$ ). También se han documentado varios fragmentos grandes de pared curva, de lo que debió ser la chimenea. Estaban en posición secundaria explicable en parte por los destrozos parciales que habría que hacer para extraer de su interior la lupia o esponja de hierro. Tales fragmentos, a diferencia de la mayoría de la campana, acabaron por el efecto desigual de los procesos pirometalúrgicos (véase próximo epígrafe) vistosamente dotados de un fino vidriado de tonalidad oscura. La excavación del horno permitió definirle una solera que, por situarse a ras de suelo, lo aleja de los denominados "hornos de reducción directa con fosa para escorias". Además se le calculó un diámetro de unos $0,40 \mathrm{~m}$ por el interior de la cámara, algo menor al propuesto para otras estructuras de reducción protohistóricas conservadas en España que más adelante referiremos. La proporción $1 / 1$, estimada a partir de la relación

\section{Corte 3.}

Sección estratigráfica nordeste-suroeste

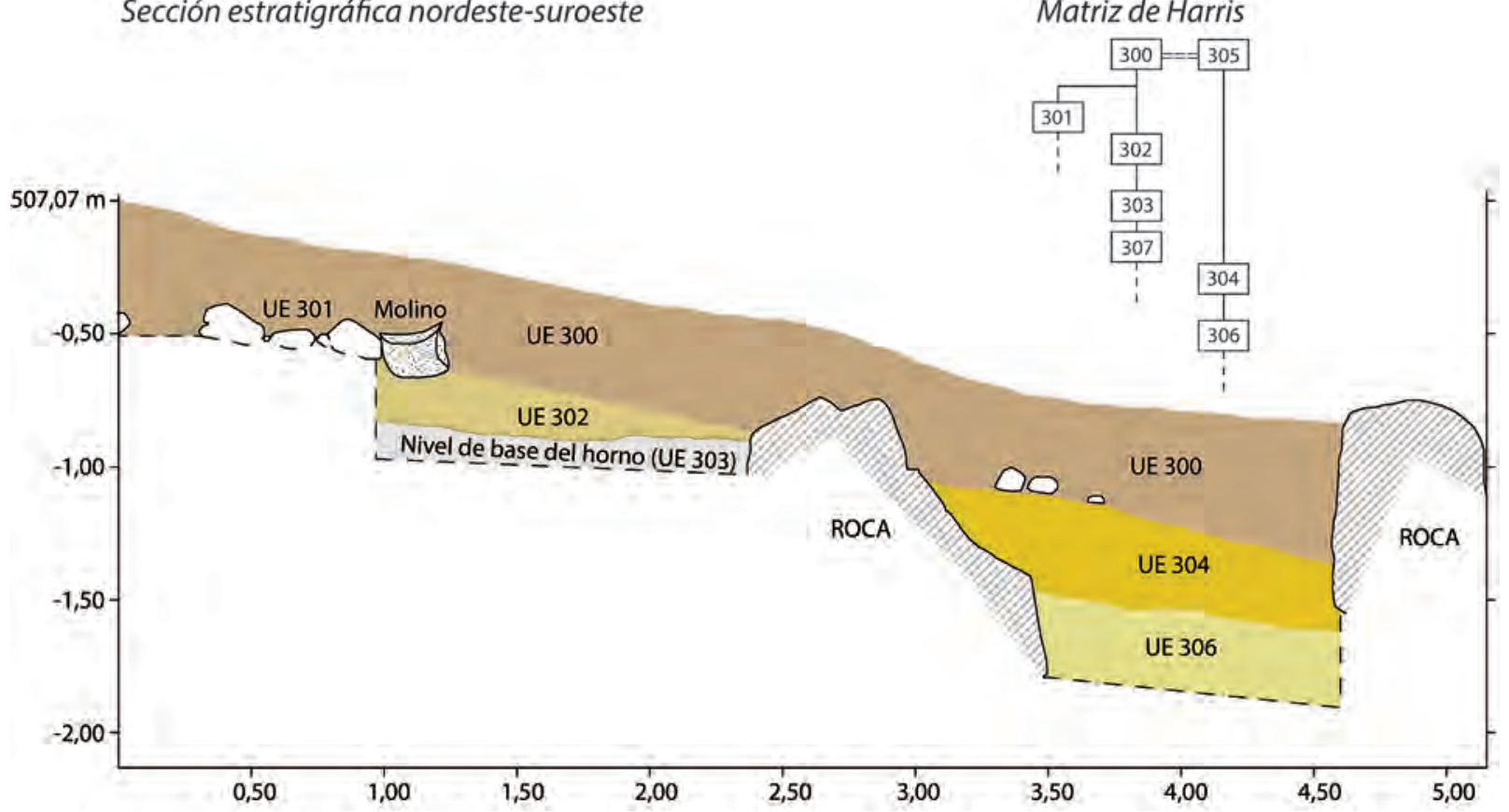

Fig. 3. Mina La Pastora. Sección estratigráfica nordeste-suroeste (en color en la edición electrónica) y matriz de Harris del Corte 3. 


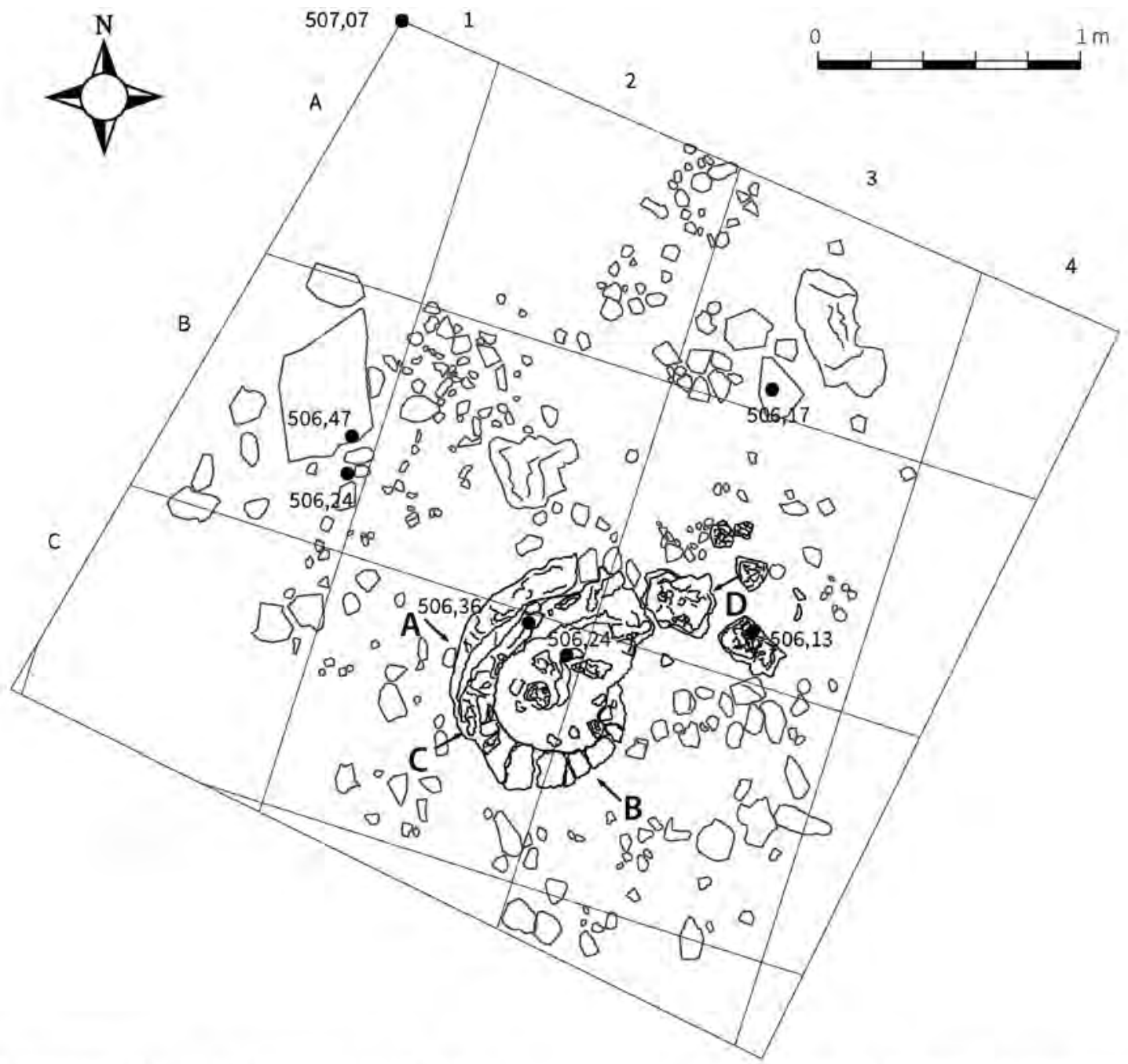

Sección C-D del horno (UE 303)

C

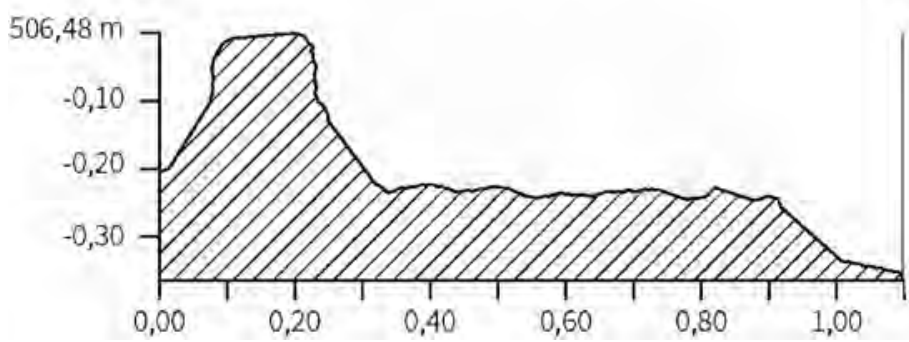

Sección A-B del horno (UE 303)

D A

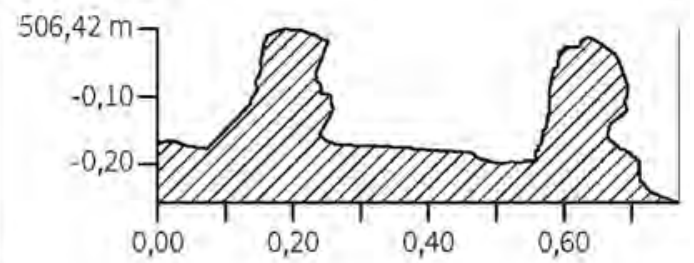

Fig. 4. Planta y secciones del horno de reducción de hierro (UE 303) de mina La Pastora (según Rodríguez et al. 2015: 130, Fig. 13A).

entre el diámetro interno de la campana y la altura de la chimenea propuesta para los hornos de Les Guàrdies y La Juncada (Gallego Cañamero 2014a:
49), acaso permitiría hipotéticamente cifrar la altura de la chimenea del de La Pastora en torno o algo superior a los $0,5 \mathrm{~m}$.

Trab. Prehist., 74, N. ${ }^{\circ}$ 2, julio-diciembre 2017, pp. 335-354, ISSN: 0082-5638 doi: $10.3989 /$ tp.2017.12198 


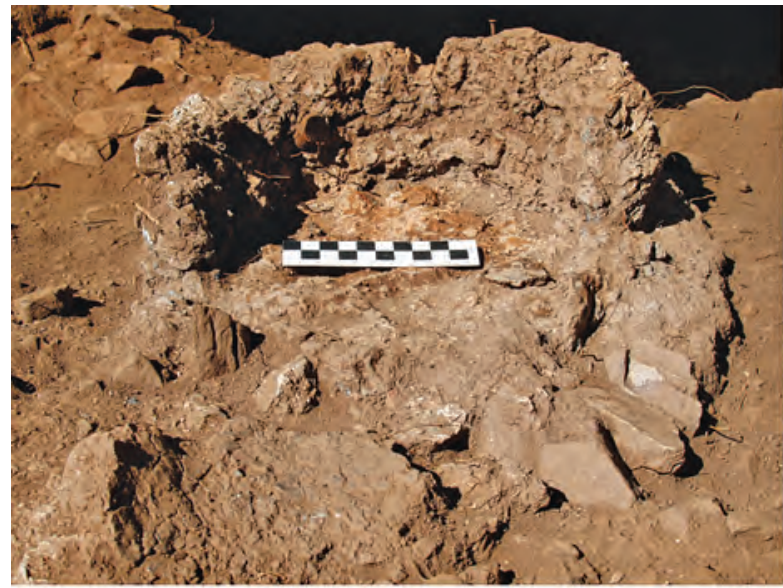

A (B)

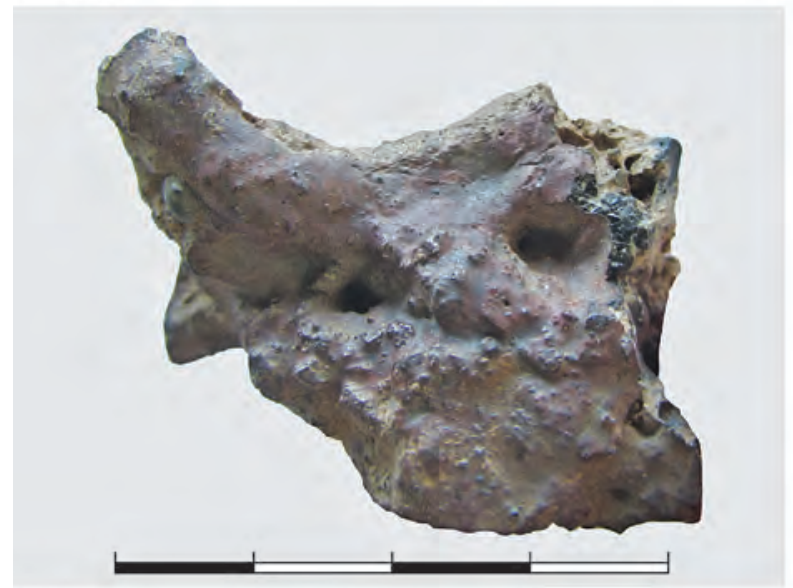

C (E)

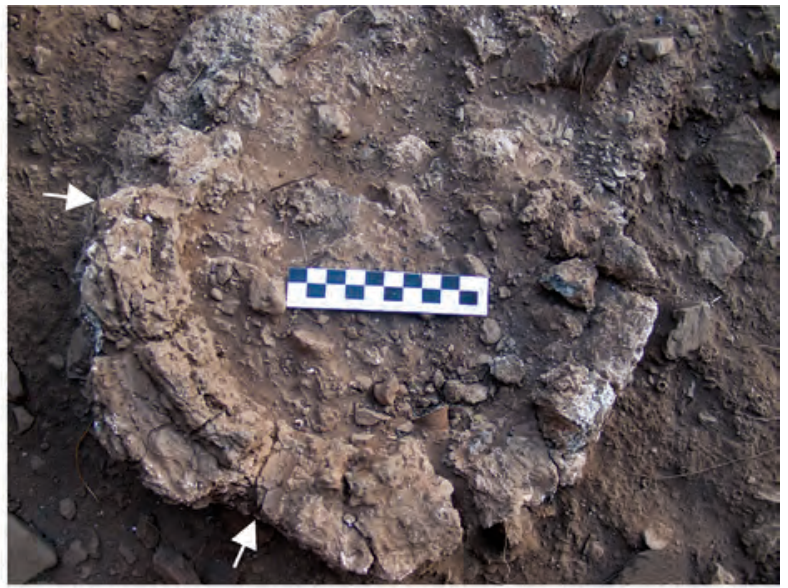

B (C)

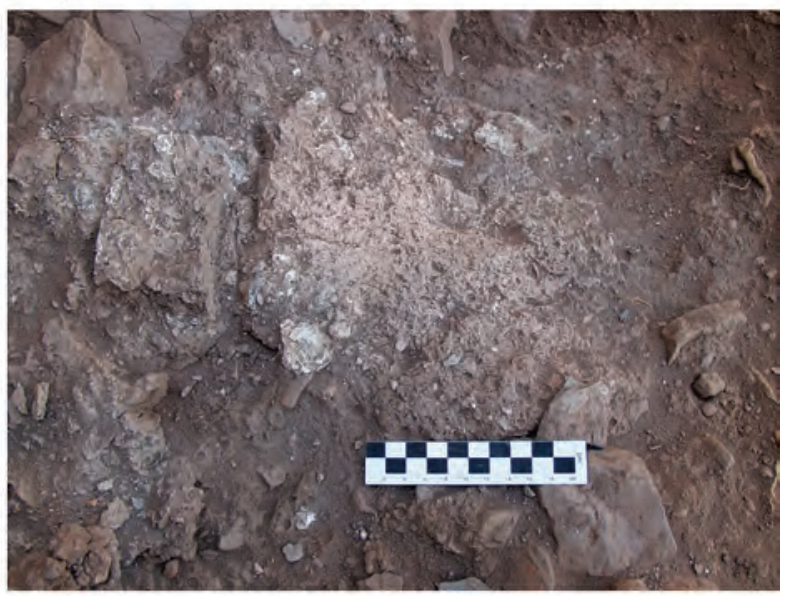

D $(\mathrm{H})$

Fig. 5. Horno de reducción de hierro de mina La Pastora: A. Vista general (UE 303); B. Localización y detalles de orificios para toberas; C. Fragmento de orificio de tobera; D. Detalle de la solera de un horno anterior (UE 307) (en color en la edición electrónica) (según Rodríguez et al. 2015: 131, Fig. 14 B, C, E, H).

Resultaron perfectamente identificables, pese a su estado incompleto, dos orificios in situ por los que se introducirían sendas toberas (Fig. 5B). Cabe sumarles al menos una tercera si valoramos un fragmento recuperado entre la ruina de la estructura y hasta especular, en proyección, con una cuarta si se tienen en cuenta su diámetro general, la posición de las conservadas y una distribución pautada de las mismas. El diámetro estimado para las toberas, en función de las improntas que permanecían en el reborde de los restos conservados, sería de algo más de $3 \mathrm{~cm}$ para la mayor, y solo algo menor para la segunda. No se ha conservado ningún buen fragmento de ellas: solo hay un posible fragmentito del extremo de una tobera, con escorificaciones adheridas (Fig. 5C). Sin embargo, el detalle de su existencia no es menor, dada la habitual dificultad para discriminar las estructuras de combustión asistidas mediante fuelles de las auto-alimentadas o de tiro natural o libre (que tomarían el aire del exterior a través de un número de toberas muy superior) cuando se parte, como se ha recordado, de un registro arqueológico casi siempre dudoso, escaso y mal conservado en sus partes aéreas (Gallego Cañamero 2014a: 40). Por fortuna, podemos aportar algunos detalles más, como la disposición de tales orificios a una altura de unos $0,13 \mathrm{~m}$ sobre el fondo interior del horno y con unos $15^{\circ}$ de inclinación. Unas toberas que, mediante la acción de fuelles, introducirían aire 
en la cámara para poder alcanzar las altas temperaturas exigidas para reducir el mineral de hierro.

Bajo dicha UE303, el proceso de excavación descubrió los restos in situ de la ya referida estructura UE307, una solera rubefactada de horno, más antigua pero de las mismas características y peor conservada, acompañada de un fragmento de pared de su correspondiente campana. Sobre estos restos apoyaba el horno más reciente (Fig. 5D). Ambas permiten integrar estos restos, como ya se ha insinuado, entre los hornos de sangrado, de cuyos subproductos nos ocuparemos enseguida.

Todo ello fue elaborado con una argamasa que incluyó una sustancia blanquecina -caolín según las analíticas-, algo de barro y cantos angulosos de cuarcita. Todos estos materiales tienen una clara procedencia local. Incluso hoy se aprecian vetas verticales de caolín en las galerías de la propia mina La Pastora abiertas por las exploraciones de los años cincuenta, que ocasionalmente asoman a la superficie.

\subsubsection{Restos materiales y cronología}

La adscripción crono-cultural de los restos pirometalúrgicos de La Pastora ha valorado radiocarbónica y tipológicamente algunas de las muestras paleobotánicas y cerámicas recuperadas. Ambas conducen a conclusiones diferentes, si bien las primeras nos merecen poco crédito, como argumentaremos a continuación. Así, una semilla de mala hierba carbonizada recuperada en el interior del horno UE303 arroja para dicha estructura una cronología del 2130 \pm 30 BP (Beta-396649), en tanto fragmentos de madera carbonizada de brezo (cf. Erica sp.) tomados junto al horno UE307, estratigráficamente más antiguo, lo fechan después, hacia 2020 \pm 30 BP (Beta-403354). Ambos resultados, que llevarían los hornos a un contexto romano-republicano, se invalidan mutuamente por ofrecernos una propuesta radiocarbónica invertida, achacable a las filtraciones de basuras y vertidos del estrato superior, favorecidas por la textura fina y suelta de toda la estratigrafía. Como ya se dijo, el abrigo donde está el horno ha sido objeto de numerosas visitas y de combustiones modernas que han convertido este sedimento en una fuente de muestreo nada propicia ni fiable para la realización de nuevas datas radiométricas. La cro- nología radiométrica efectuada, que nos lleva a época romana, nos resulta también inviable dada la absoluta ausencia de fragmentos cerámicos de dicho periodo en el contexto excavado.

Por el contrario, salvando los barros modernos de los niveles superficiales (7 fragmentos) y un par de piezas rodadas de tipología calcolítica, las familias y formas cerámicas más numerosas y definidas del Corte 3 (38 fragmentos) $-y$ en particular las de los estratos de uso y amortización de los hornos (UEs 302, 303 y 307)- nos remiten a un horizonte Orientalizante (Fig. 6). Como ya sucediera en todas las fases protohistóricas del poblado de la Sierra del Aljibe, principalmente, hay producciones modeladas que trazan un panorama tecnológico también dominado por las toscas sobre las cuidadas-semicuidadas. Entre estas últimas, resultan reconocibles algunos fragmentos de cuencos carenados (en distintas variantes de la forma A.1, siguiendo la terminología empleada en el estudio del poblado de la Sierra del Aljibe y otros poblados protohistóricos de la penillanura cacereña) (Rodríguez Díaz y Pavón Soldevila 1999; Enríquez Navascués et al. 2001), cazuelas carenadas (A.2) y cuencos hemisféricos ligeramente entrantes (A.4.c). También se distinguen, entre las cerámicas a mano toscas, fragmentos de algunos de los tipos de ollas de borde vuelto más comunes en este entorno (C.1 y C.2), a veces con tratamiento escobillado, así como fuentes y cuencos de casquete esférico (C.3). En las producciones torneadas, cabe destacar algunos ejemplares de cerámica gris, como ciertos vasos de pequeño tamaño que emulan la morfología de los cuencos tradicionales del Bronce Final, pequeñas urnas (versiones reducidas de la forma F.4) y bases planas acaso de urnas o, más probablemente, de cuencos-platos (F.1). En su globalidad, son elementos representativos de las fases Aliseda II y III del poblado de la Sierra del Aljibe, encuadradas en los períodos Orientalizante y Postorientalizante (siglos VII-VI/VI-V a.C.). Puntualmente vemos también en el lote producciones oxidantes lisas, destacando el fragmento de urna tipo "Cruz del Negro" asociado al horno más antiguo (UE307) con ciertos rasgos específicamente reconocidos en algunos subtipos de la necrópolis de Medellín (como la tendencia globular del cuerpo o el cuello aún no exvasado o acampanado) que permitirían acotarlo más en concreto en la fase Aliseda II del poblado de la Sierra del Aljibe. 

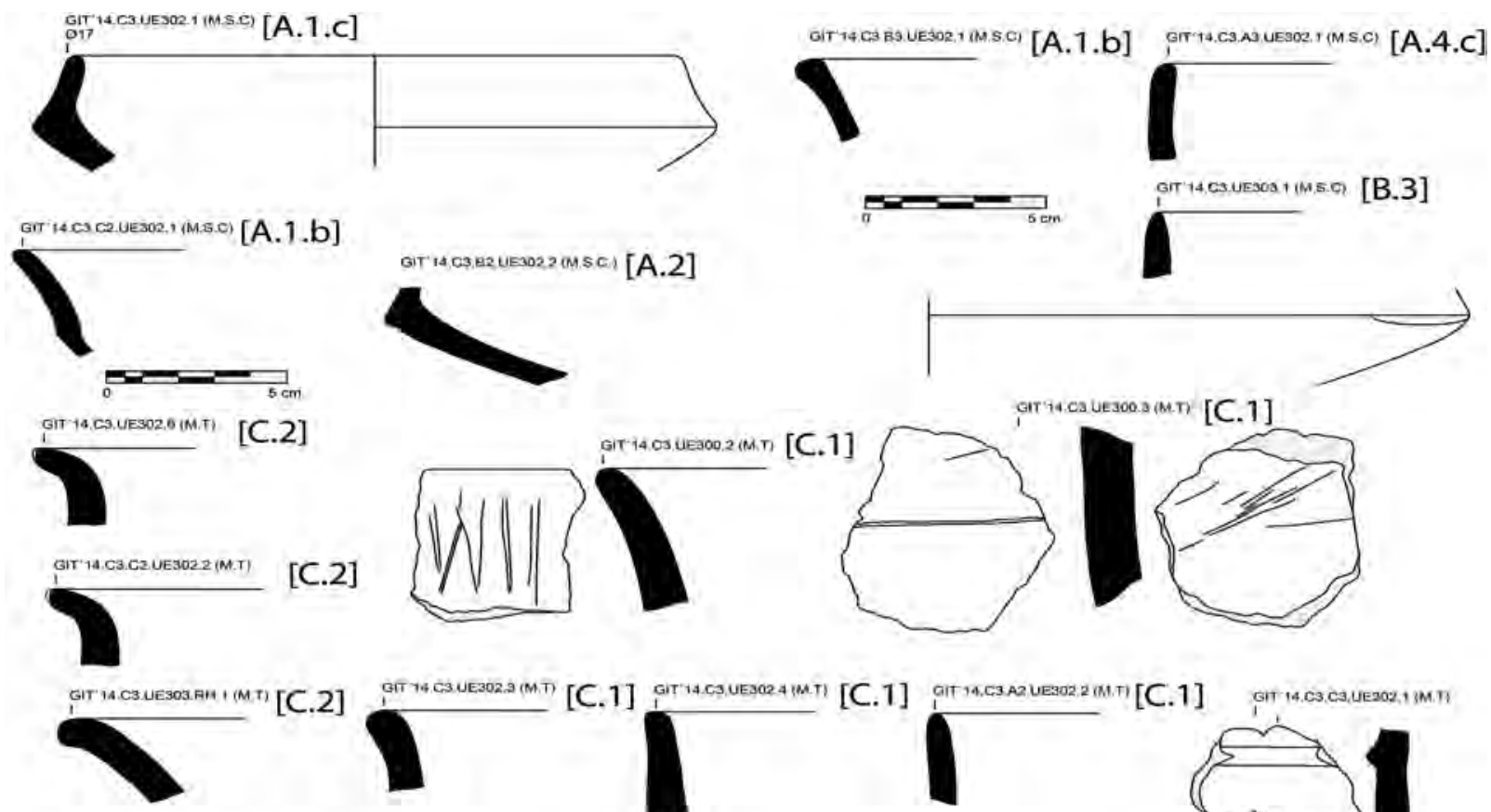

A.1.b]
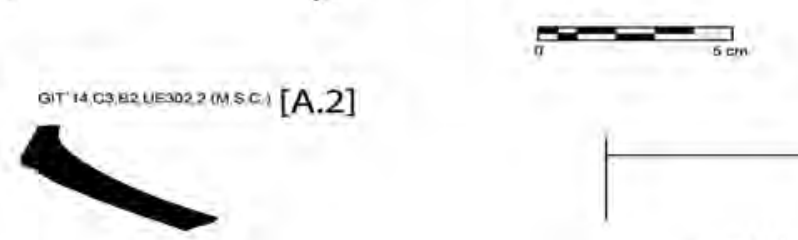

[B.3]

[C.2]
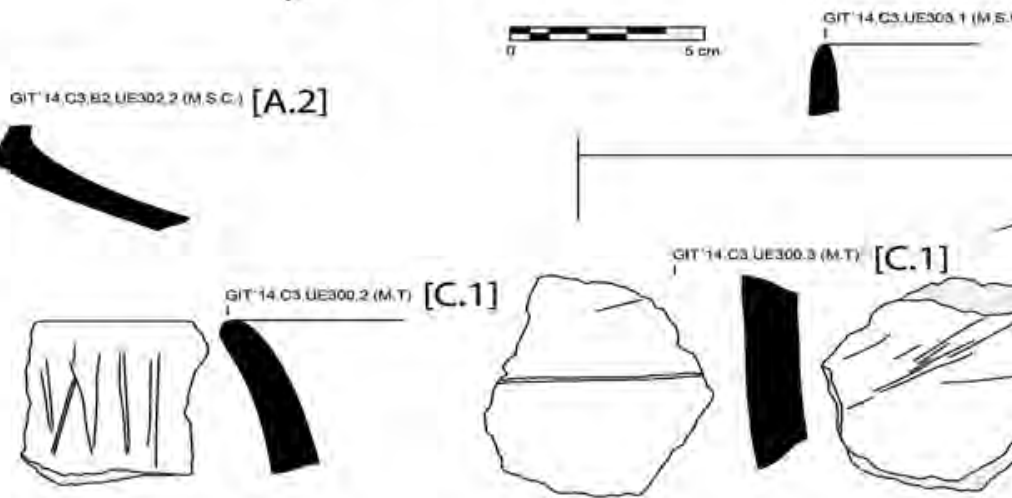

$[\mathrm{B} .3]$

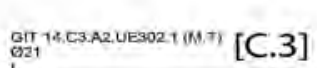

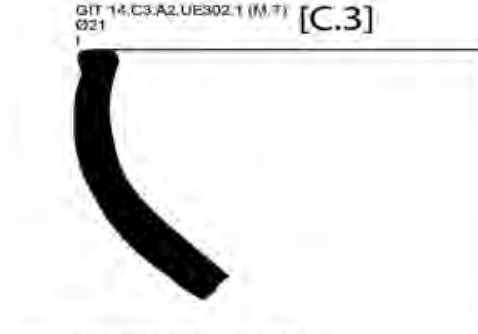

[C.2]

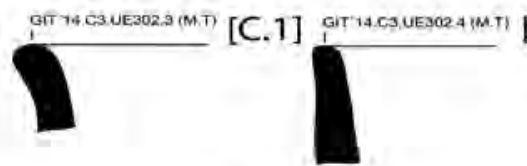

[C.1]

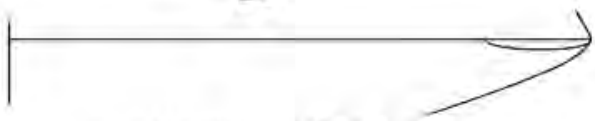

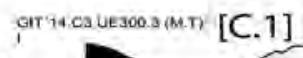
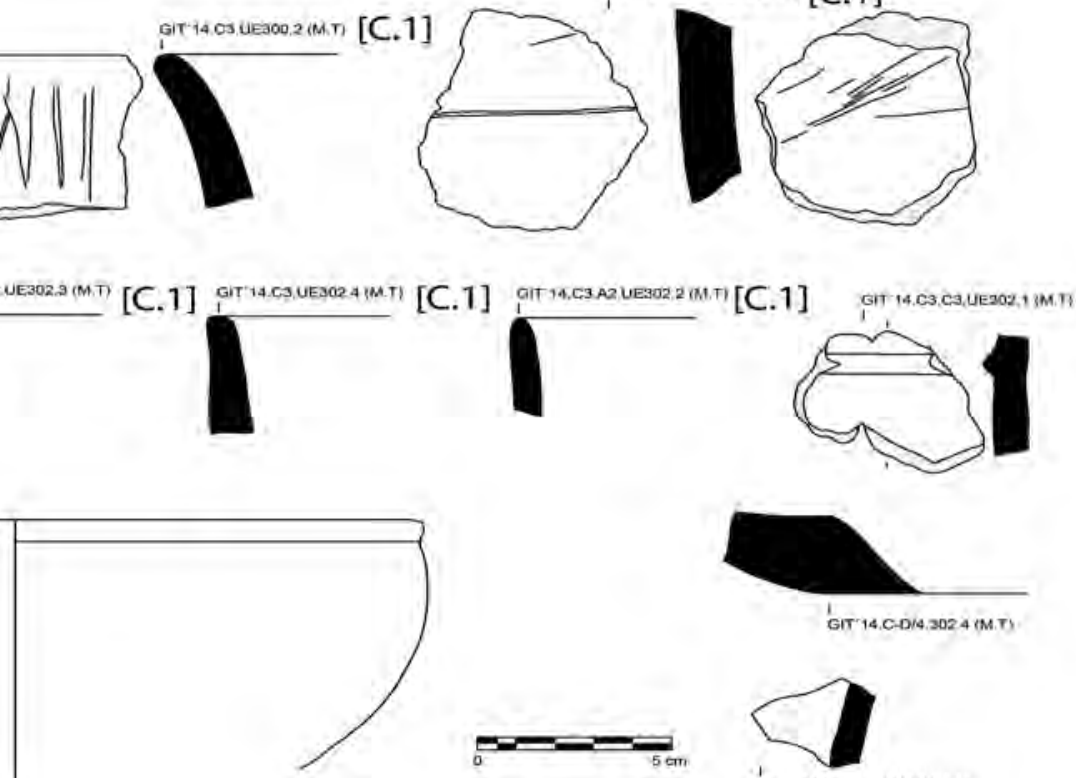

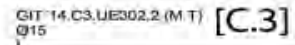

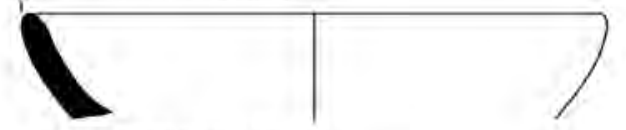

gir 140.043025 into $[$ [C.3]

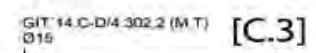
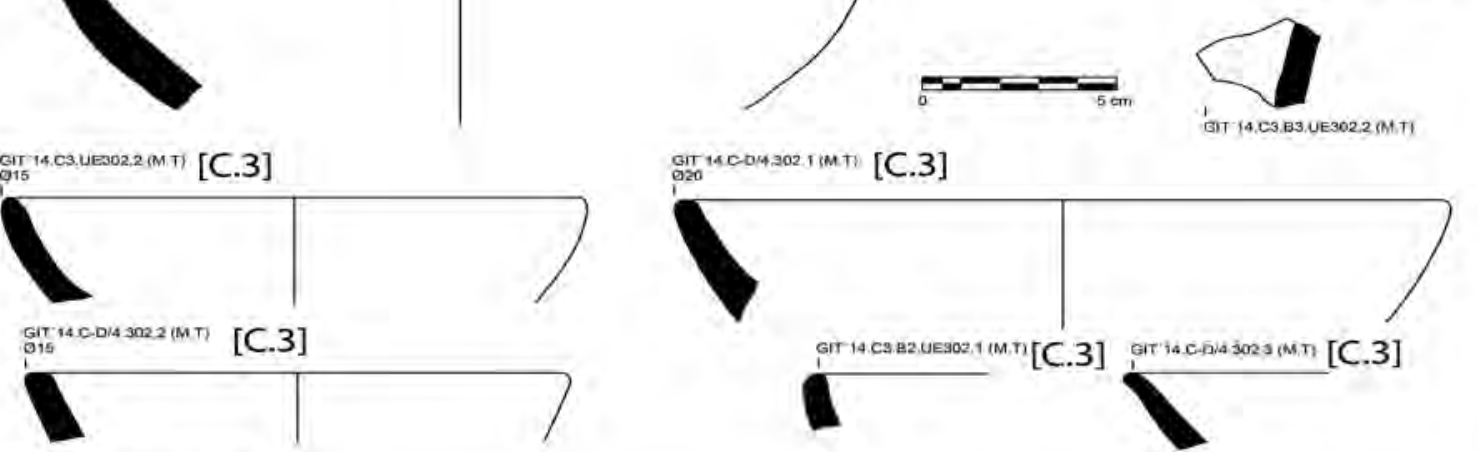

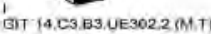
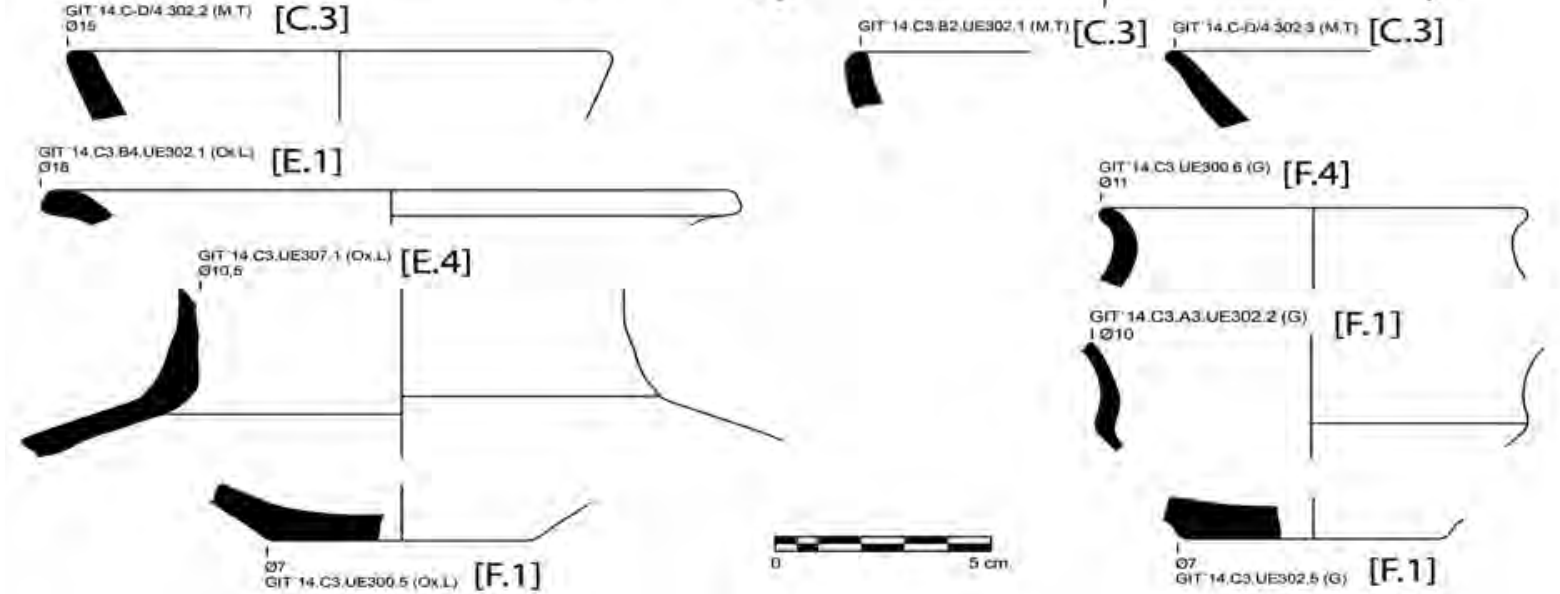

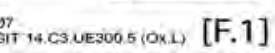

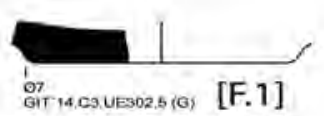

Fig. 6. Cerámicas protohistóricas recuperadas en el contexto de amortización de los hornos de reducción de hierro del Corte 3 de mina La Pastora (según Rodríguez et al. 2015: 132, Fig. 15).

Trab. Prehist., 74, N. ${ }^{\circ} 2$, julio-diciembre 2017, pp. 335-354, ISSN: 0082-5638 doi: $10.3989 /$ tp.2017.12198 
Como ya hemos indicado, tanto en el mundo ibérico (Gallego Cañamero 2014a: 41) como en el contexto norteño (Camino Mayor y Villa Valdés 2014: 68), se siguen tendiendo a considerar los hornos con canal de drenaje para las escorias una innovación introducida durante la época romana. En Aliseda, como acabamos de ver, el material arqueológico asociado a los hornos de La Pastora apoya por el contrario una adscripción protohistórica. Por su parte, en el contexto mediterráneo levantino, en absoluto ajeno a los colonizadores orientales de la Península Ibérica cuyos influjos alcanzaron el actual territorio extremeño, se ha sugerido su existencia desde comienzos del I milenio A.C. a partir de las escorias de sangrado recuperadas en Tell Hammeh (Jordán, Israel) (Veldhuijzen y Rehren 2007: 193-194).

\section{EL PROCESO MINERO-METALÚRGICO}

Abordaremos en este apartado algunos de los elementos del proceso minero-metalúrgico que han podido ser documentados: el mineral, el combustible y las escorias.

\subsection{El mineral}

Nada conocemos de la tipología y de la tecnología extractiva de época protohistórica en La
Pastora por las transformaciones provocadas por las labores modernas, pero podemos aportar una primera aproximación a la procedencia y composición del mineral. A expensas de poder ampliar el registro en el futuro, los minerales de hierro (Fig. 7A) proceden de vetas ferríferas encajadas en cuarcita contaminada por la descomposición de dichos minerales. Son óxidos e hidróxidos que, una vez desprovistos de la ganga, retienen en torno a un $4 \%$ de impurezas; se componen básicamente de hematita y goethita, con pequeñas contribuciones de fosfatos y sulfatos (Rovira Lloréns y Renzi 2015: 347). La figura 7B ilustra una muestra constituida por una matriz de goethita con formaciones botroidales de hematita. Son especies comunes de la mineralización de la mina La Pastora (Rebollada Casado et al. 2010: 250).

\subsection{El combustible}

El estudio antracológico realizado en el Corte 3 de La Pastora por uno de nosotros ha permitido analizar un total de 172 restos de carbón procedentes de las UEs 302, 303 y 307 (80, 82 y 10 en cada caso), correspondientes al nivel de uso, al horno más reciente y a los restos de un segundo horno más antiguo, respectivamente (Tab. 1). Con las matizaciones a las que obliga un registro tan escaso (en su conjunto y por UEs), apuntamos una serie de cuestiones que, por reiterativas en el

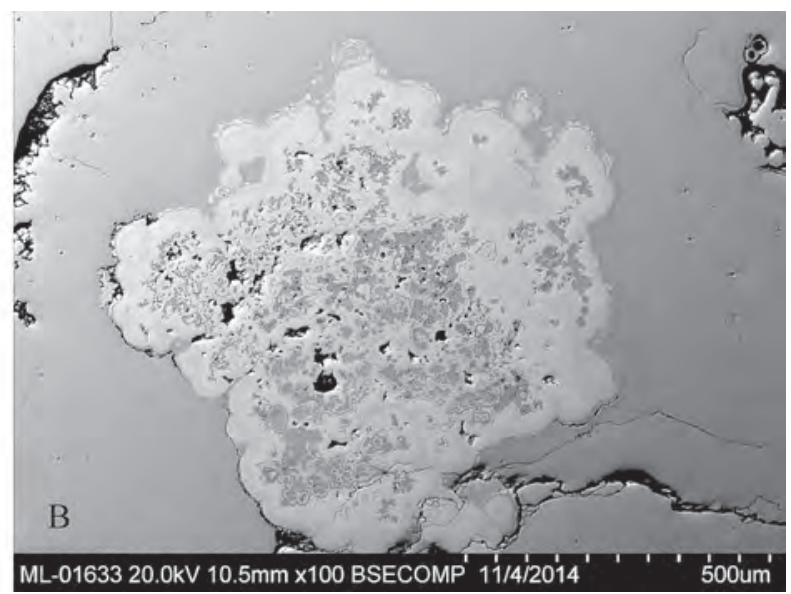

Fig. 7. Hallazgos del entorno del horno de reducción de hierro de mina La Pastora: A. Fragmentos de mineral de hierro. Óxidos e hidróxidos de hierro encajados en cuarcita (en color en la edición electrónica); B. Mineral de hierro. Una matriz masiva de goethita con inclusiones botroidales de hematita (imagen del microscopio electrónico de barrido, electrones retrodispersados). 


\begin{tabular}{|c|c|c|c|c|c|c|c|c|c|c|c|c|c|c|}
\hline Unidad estratigráfica & \multicolumn{6}{|c|}{ UE. 302} & \multirow{2}{*}{\multicolumn{5}{|c|}{$\begin{array}{c}\text { UE. } 303 \\
\text { En torno al } \\
\text { Horno } 1\end{array}$}} & UE. 307 & \multirow{3}{*}{ Total } & \multirow{3}{*}{$\%$} \\
\hline Relación espacial & \multicolumn{2}{|c|}{ B2 } & \multicolumn{3}{|c|}{ B3 } & \multirow{2}{*}{\begin{tabular}{|c|} 
C3 \\
M12 \\
\end{tabular}} & & & & & & \multirow{2}{*}{$\begin{array}{c}\begin{array}{c}\text { En } \\
\text { torno al } \\
\text { Horno 2 }\end{array} \\
\text { M1 }\end{array}$} & & \\
\hline Taxa/Muestra & M8 & M10 & M7 & M9 & M11 & & M2 & M3 & M4 & M5 & M6 & & & \\
\hline Arbutus unedo & & & & & 2 & 2 & & 1 & & & 1 & & 6 & 3,49 \\
\hline cf. Asparagus sp. & & & & & 1 & & & & & & & & 1 & 0,58 \\
\hline Cistaceae sp. & & & & & 1 & & & & & & & & ? & 116 \\
\hline cf. Cistaceae sp. & & & & & & & & & & & 1 & & 2 & 1,10 \\
\hline Erica sp. & & 1 & & & 6 & 2 & & 2 & 3 & 6 & 16 & 3 & & \\
\hline cf. Erica sp. & & 1 & & & & & 1 & 1 & & 2 & & 4 & 年 & 21,51 \\
\hline Leguminosae sp. & & & & & & 1 & & & & & & & 1 & 0,58 \\
\hline Olea europaea & & & & & 11 & 2 & & & & & 11 & & 25 & 1453 \\
\hline cf. Olea europaea & & 1 & & & & & & & & & & & 20 & נינ, \\
\hline Phyllirea/Rhamnus & & & & & 4 & & & & & & & & 2 & 2,33 \\
\hline Pistacia lentiscus & & & & & 2 & & & & & & & & 2 & 1,16 \\
\hline Quercus ilex-coccifera & 1 & 1 & 1 & & 2 & 2 & & & & & 4 & & 11 & 6,40 \\
\hline Quercus suber & & & & & 2 & & & & & & & & 3 & 74 \\
\hline cf. Quercus suber & & 1 & & & & & & & & & & & ( & ו ו \\
\hline Quercus sp. t. perennifolio & & & & & & & & 1 & & & & & 1 & 0,58 \\
\hline Quercus sp. t. caducifolio & & & & & 1 & & & & & & & & 1 & 0,58 \\
\hline Rubus ulmifolius & & 1 & & & & & & & & & & & 1 & 0,58 \\
\hline Ruscus aculeatus & & & & & & & & & 1 & & & & 1 & 0,58 \\
\hline Indeterminable & 4 & 4 & & 4 & 18 & 1 & & 5 & 6 & 3 & 17 & 3 & 65 & 37,79 \\
\hline Total muestra & 5 & 10 & 1 & 4 & 50 & 10 & 1 & 10 & 10 & 11 & 50 & 10 & 12 & מ \\
\hline Total UE & & & 8 & & & & & & 82 & & & 10 & 172 & \\
\hline
\end{tabular}

Tab. 1. Resultados antracológicos de los hornos del Corte 3 de mina La Pastora.

registro, podrían relacionarse con un uso selectivo del combustible para fines siderúrgicos.

En primer lugar señalamos las similitudes taxonómicas entre las paleofloras identificadas en el antracoanálisis de este Corte y las de las secuencias del poblado de la Sierra del Aljibe o del paraje ritual de Las Cortinas (Grau Almero et al. 1998; Grau Almero 1999; Duque Espino 2004, 2011, 2015). Las similitudes, sin embargo, no se corresponden con la valoración cuantitativa de esos taxones, pues parece reiterarse en La Pastora el predominio del grupo de fragmentos indeterminables $(37,79 \%)$, seguido del uso mayoritario de la madera de brezo (Erica sp.) $(27,91 \%)$ y, en menor medida, del olivo/acebuche (Olea europea) $(14,53 \%)$, que juntos suman algo más del $80 \%$ de los valores relativos del análisis. Completan el registro las quercíneas perennifolias (Q. ilex-coccifera, $Q$. suber, $Q$. sp. t. perennifolio), madroños (Arbutus unedo), olivillas/aladiernos (Phillyreal Rhamnus), lentiscos (Pistacia lentiscus), jaras (Cistaceae sp.) y, de forma casi testimonial, restos de monocotiledóneas (Esparraguera -cf. Asparagus sp.- y rusco - Rucus aculeatus-, quercíneas caducifolias $(Q$. sp. t. caducifolio) y zarzamoras (Rubus ulmifolius) (Fig. 8).

$\mathrm{La}$ alta tasa de carbones indeterminables parece provocada por la fusión de la estructura anatómica de los fragmentos, la mayoría de las veces asociada al fuerte proceso de vitrificación sufrido por el combustible. Este proceso en grados moderado y bajo también ha sido muy frecuente 

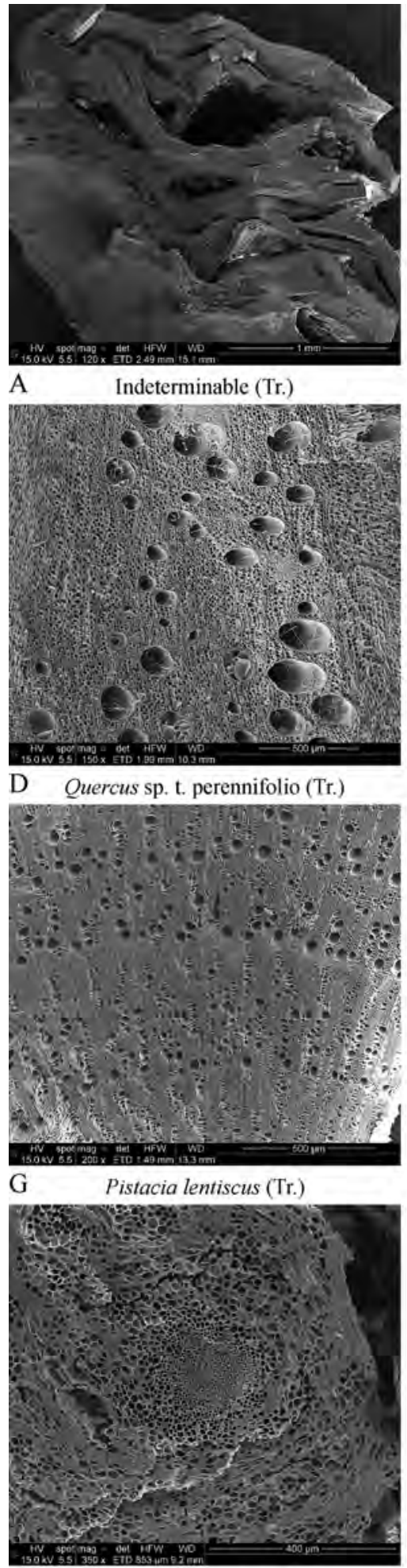

J Ruscus aculeatus (Tr.)
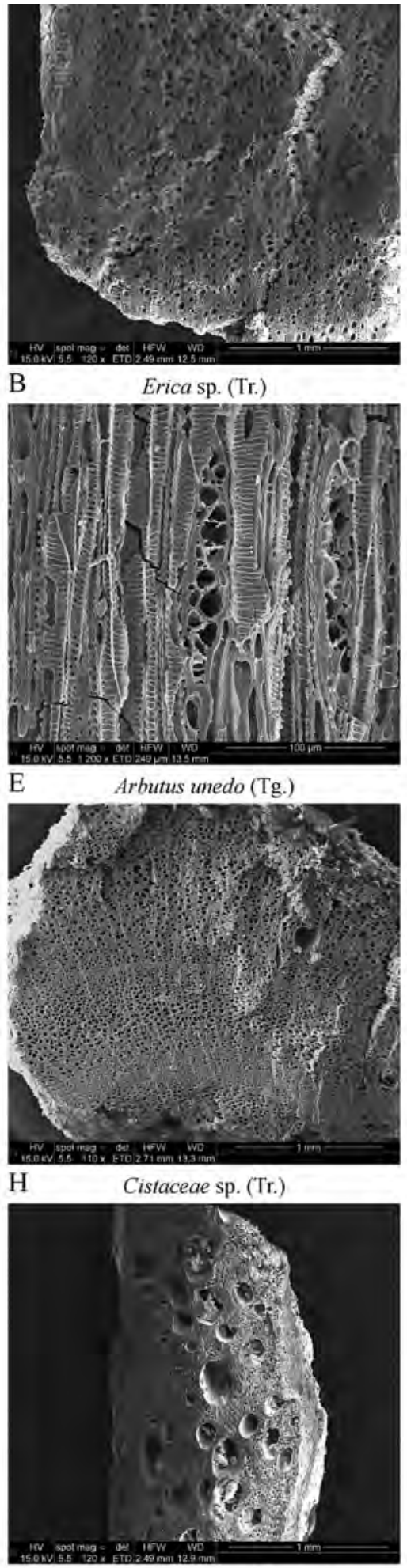

K Quercus sp. t. caducifolio (Tr.)
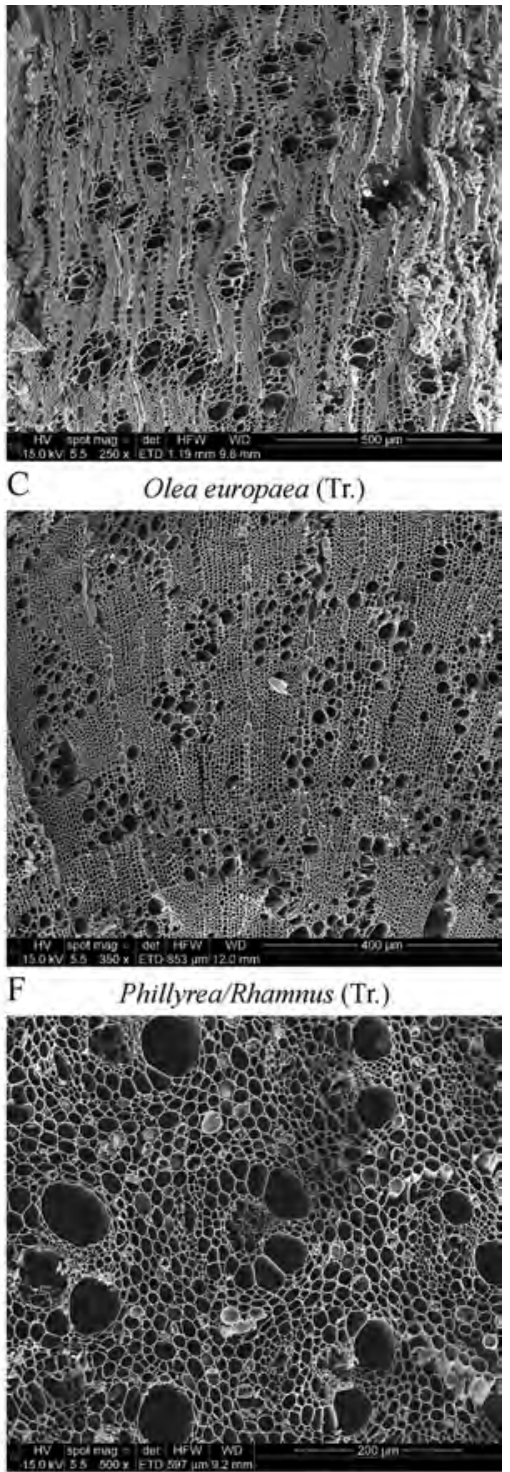

I cf. Aspragus sp. (Tr.)

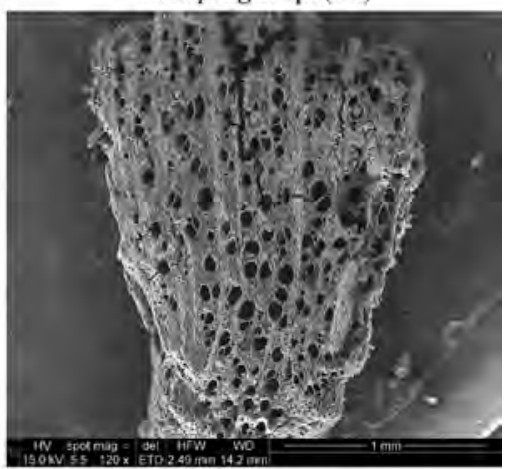

L Rubus ulmifolius (Tr.)

Fig. 8. Taxones antracológicos documentados en el microscopio electrónico de barrido, procedentes de los hornos de reducción de hierro del Corte 3 de mina La Pastora (Tr.: plano transversal; Tg.: plano longitudinal tangencial).

Trab. Prehist., 74, N. ${ }^{\circ} 2$, julio-diciembre 2017, pp. 335-354, ISSN: 0082-5638 doi: $10.3989 /$ tp.2017.12198 
en los restantes fragmentos analizados, pero ha permitido conservar gran parte de los criterios anatómicos para la determinación de los mismos.

No se conocen bien las causas que provocan la vitrificación, pero los estudios realizados apuntan a un proceso de combustión a altas temperaturas combinado con una carbonización lenta en un medio reductor de maderas con una tasa de humedad elevada por falta de secado previo o por su uso en verde (Carrión Marco 2004, 2005; Carrión Marco y Badal García 2005). La vitrificación no suele aparecer en estudios antracológicos de yacimientos arqueológicos, siendo más habitual, aunque no sistemática (Théry-Parisot 2001), en contextos de incendios naturales ${ }^{2}$ y de carboneras de época histórica ${ }^{3}$. En La Pastora, los datos aportados por el carbón procedente de la actividad siderúrgica demuestran que más del $60 \%$ de los fragmentos analizados están afectados por la vitrificación en sus diferentes gradientes (Marguerie et al. 2010). El que esto no se haya observado hasta ahora en antracoanálisis de contextos arqueológicos cercanos cronológica o geográficamente (Duque Espino 2004) permitiría apoyar el ambiente reductor de las combustiones al menos como una de las causas de vitrificación.

Uno de los problemas de las experimentaciones para la obtención de hierro en hornos similares a estos de La Pastora es la imposibilidad de alcanzar las altas temperaturas deseadas. Estas, sin embargo, podrían obtenerse bien con el uso de fundentes, uso alejado de los resultados metalográficos conseguidos de los hornos protohistóricos (Rovira Lloréns y Burillo Mozota 2005), bien con el empleo de carbón y no de madera, al menos para el ejercicio de esta actividad, ya que triplicaría el poder calorífico de las combustiones (Marcos Martín 1989: 98). No contamos con referentes arqueológicos protohistóricos directos para asumir la hipótesis de la fabricación de carbón, pero podríamos apuntar

2 Thinon, M. 1992: L'analyse pédoanthracologique. Aspects méthodologies et applications. Thèse d'État, inédita, Université d'Aix-Marseille III; Tardy, C. 1998: Paleoincendies naturels, feux anthropiques et environnements forestiers de Guyane française du tardiglaciaire à l'holocène récent. Approche chronologique et anthracologique. Thèse d'État, inédita, l'Université de Montpellier II.

${ }^{3}$ Fabre, L. 1996: Le charbonnage historiques de la chênaie à Quercus ilex L. (Languedoc, France): consequences écologiques. Thèse d'État, inedita, Université de Montpellier II. su obtención por métodos simples (FAO 1983; Wolf y Vogel 1985; Marcos Martín 1989) para su posterior uso en hornos reductores siderúrgicos como la causa principal de la alta presencia del proceso de vitrificación en nuestro análisis. Las principales especies utilizadas (brezo y acebuche/ olivo) apoyan la idea del proceso selectivo. Los estudios etnográficos y las fuentes históricas indican reiteradamente que ambas especies fueron algunas de las más estimadas y utilizadas en la fabricación de carbón con un destino siderúrgico tradicional hasta el siglo XIX en el territorio peninsular (Galán Cela et al. 1998; Blanco et al. 2000; López González 2001; Izco et al. 2006; Ramos Santos 2006; Pascual Mayoral y García Ruiz 2007; etc.).

\subsection{Producto y escorias}

El resultado del proceso siderúrgico se sustancia en el producto (lupias o esponjas), y el subproducto (escorias). A falta de las primeras, nos centraremos en el análisis de las segundas. Dada la aludida falta de fosa para escorias, un factor determinante para incluir tipológica y tecnológicamente La Pastora entre los bajos hornos de sangrado con canal de drenaje ha sido el estudio morfológico de las doce escorias recuperadas junto al horno, cuya morfología y aspecto son propios de las de sangrado. Tales escorias se solidifican en el exterior del horno, tras abrir una piquera en su parte baja para que fluya la escoria semilíquida y viscosa formada en su interior. Las superficies muestran una inconfundible morfología de cordones cuya cierta orientación longitudinal sugiere que la colada fluyó, por un canal ligeramente inclinado de sección en "V" muy abierta, hacia un hipotético receptáculo (aquí no documentado) situado a un nivel más bajo que la solera del horno. Los fragmentos recuperados al excavar esta zona de La Pastora muestran invariablemente esa misma orientación de los cordones, de lo que cabe inferir que no se llegó a formar una torta de escoria, sino un reguero, y por tanto que la escoria evacuada en cada hornada no debía de ser mucha.

Las escorias de sangrado (Fig. 9) tienen composiciones mineralógicas y químicas muy semejantes entre sí, aunque con algunas peculiaridades 


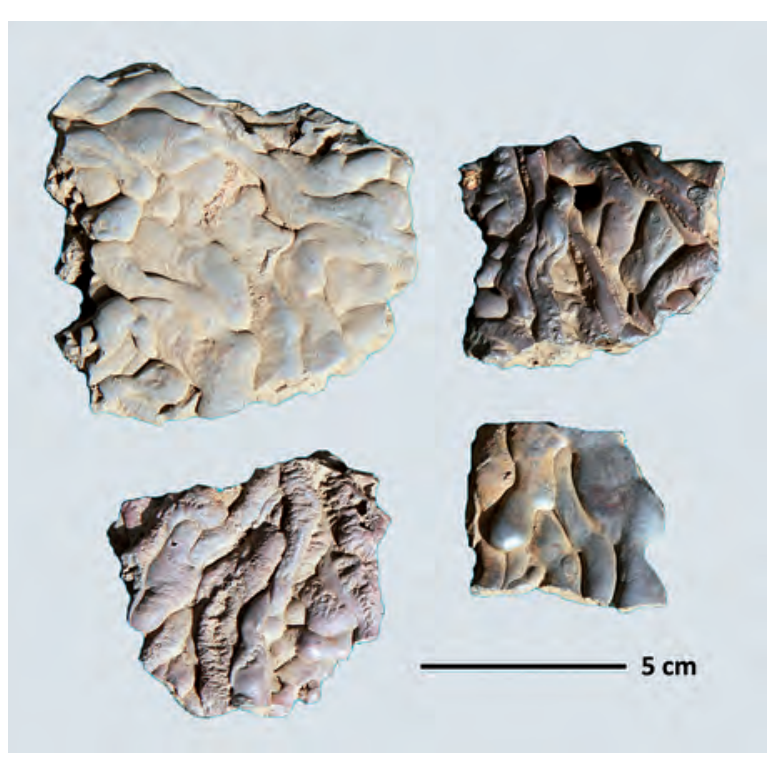

Fig. 9. Cuatro fragmentos de escoria de sangrado recuperados junto al horno de reducción de hierro del Corte 3 de mina La Pastora. Obsérvese la orientación de los cordones de su superficie. Las diferencias de coloración se deben a distintos grados de limpieza (en color en la edición electrónica) (según Rovira y Renzi 2015: 344, Fig. 1B). que detallaremos. Todas reaccionan ante el imán, lo cual nos advierte de que algún compuesto de hierro trivalente está presente. Los compuestos químicos predominantes son la sílice y los óxidos de hierro y aluminio; el óxido de calcio está en proporciones bajas pero, en cambio, hay cantidades de óxido de titanio inusualmente altas (pueden superar el $5 \%$ en peso). Las composiciones detalladas de 15 muestras analizadas pueden consultarse en Rovira Lloréns y Renzi (2015: 344-345, Fig. 2). Su cristalografía tiene como componentes principales la fayalita (silicato de hierro) y la wüstita (óxido de hierro divalente). Como veremos, la abundancia relativa de la wüstita permite establecer grupos de escorias.

Una peculiaridad de estas escorias es la presencia de un mineral del grupo de las espinelas. En realidad no es una espinela sino una mezcla de hercinita (espinela verdadera) y magnetita, que también ha sido identificada en otras escorias raras (Severin et al. 2011: 986). A este mineral deben estas escorias su propiedad de reaccionar ante el imán. Todas las muestras analizadas lo
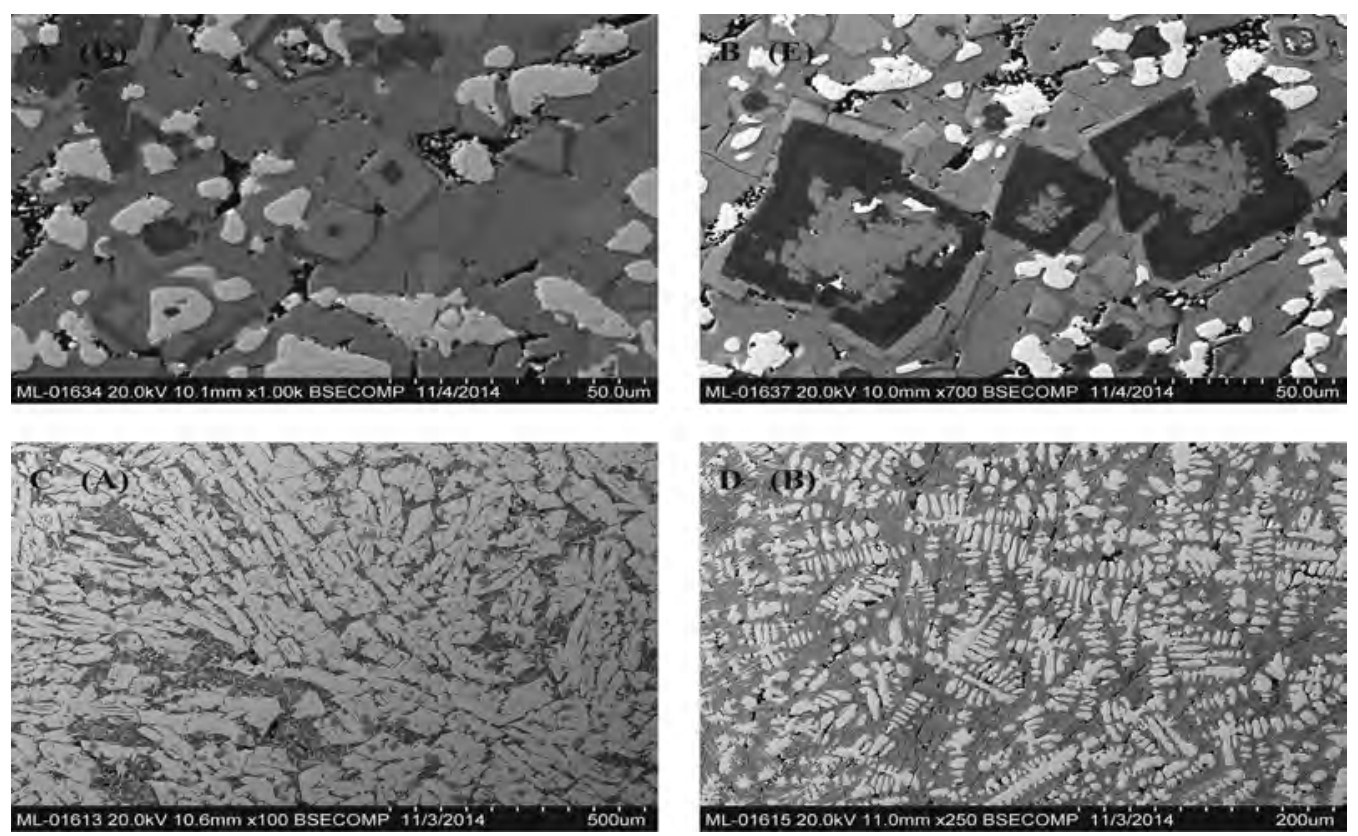

Fig. 10. Fragmentos de escoria de sangrado recuperados junto al horno de reducción de hierro del Corte 3 de mina La Pastora. Imágenes del microscopio electrónico de barrido, electrones retrodispersados (según Rovira y Renzi 2015: 346, Fig. 3 A, B, D, E): A. Microestructura, cristales nucleados de sección poligonal debidos a interacciones entre espinela, magnetita y óxido de titanio; B. Microestructura, cristales nucleados de sección poligonal debidos a interacciones entre espinela, magnetita y óxido de titanio; C. Formaciones de fayalita (de color gris claro) y cristales de espinela (de color gris oscuro), los intersticios de los cristales de fayalita están ocupados por vidrio de relleno; D. Abundante wüstita dendrítica (color blanco) en una matriz predominantemente fayalítica.

Trab. Prehist., 74, N. ${ }^{\circ}$ 2, julio-diciembre 2017, pp. 335-354, ISSN: 0082-5638

doi: $10.3989 /$ tp.2017.12198 
contienen, en formaciones cristalinas nucleadas de sección poligonal más o menos regular (Fig. 10A). El núcleo es espinela que ha captado titanio probablemente en forma de óxido y está recubierto por un material rico en hierro y titanio que parece responder a una interacción hercinitaulvita, reacción que Severin et al. (2011: 986-987) estudiaron en detalle. Algunos cristales son más complejos, mostrando en su núcleo un compuesto cuya morfología recuerda las microdendritas de magnetita, pero cuya composición es idéntica a la del cerco (Fig. 10B).

Las escorias se agrupan en las predominantemente fayalíticas (Fig. 10C) y las que contienen junto a la fayalita cantidades importantes de wüstita (Fig. 10D). La representación gráfica de las composiciones globales de las escorias en un diagrama ternario de equilibrio de fases $\mathrm{FeO}$ $\mathrm{SiO}_{2}-\mathrm{CaO}$, convenientemente recalculadas para este fin según Bachmann (1982), muestra que los puntos se alinean junto al eje hierro-silicio debido a su bajo contenido en calcio, con la wüstita como principal diferenciador (Fig. 11). En el gráfico caen lejos de la zona del olivino, que es la de las composiciones ideales de las escorias de sangrado. Ello podría interpretarse como un cierto rasgo de primitivismo que un fundidor experto habría resuelto fácilmente añadiendo a

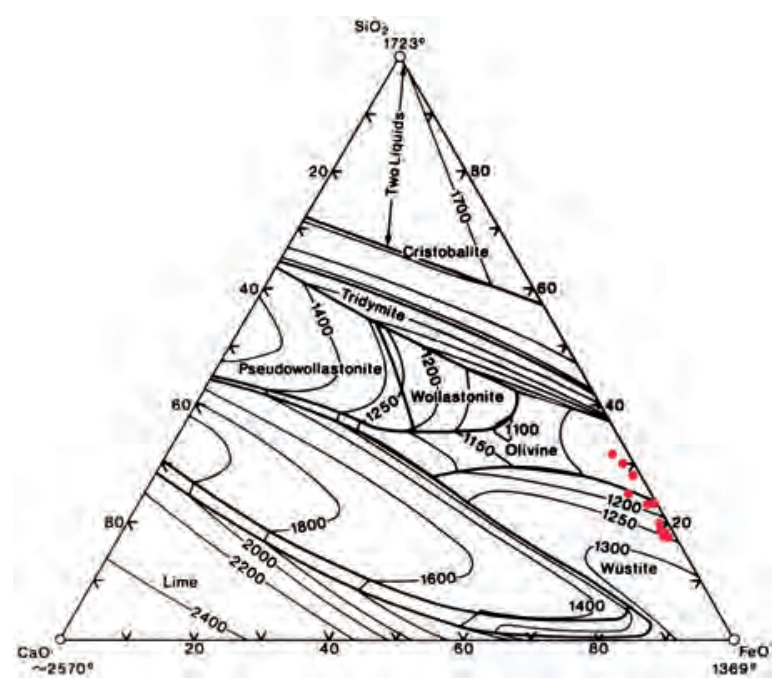

Fig. 11. Proyección de las composiciones de las escorias de mina La Pastora en un diagrama ternario de equilibrio de fases $\mathrm{FeO}-\mathrm{SiO} 2-\mathrm{CaO}$. Explicación en el texto (en color en la edición electrónica) (según Rovira y Renzi 2015: 351, Fig. 6 A). la carga del horno algo de caliza como fundente para desplazar las composiciones hacia la zona del olivino. Afortunadamente, aun sin contar con la adición de fundentes, se conseguía obtener una escoria pastosa evacuable dentro de un rango de temperaturas comprendido entre $1.150^{\circ} \mathrm{y}$ $1.250^{\circ} \mathrm{C}$, perfectamente asequible en un horno de pequeñas dimensiones ventilado con tres o cuatro toberas.

El proceso de escorificación en las fundiciones del horno de La Pastora resultó sorprendente cuando se estudió en detalle (Rovira Lloréns y Renzi 2015: 347-349). Dio la clave el material constructivo del horno, un caolín que yace en vetas y bolsadas en las inmediaciones de la propia mina. El dato que nos puso sobre la pista fue la anormal cantidad de titanio en la escoria, un elemento ausente en el mineral de hierro de la mina. En cambio el caolín con el que se construyó el horno contiene más del $2 \%$ de $\mathrm{TiO}_{2}$ (Rovira Lloréns y Renzi 2015: 348, Fig. 5B). Resumiendo, la escoria es resultado de una fuerte interacción del mineral de hierro con el caolín de la pared del horno, a alta temperatura, en la zona correspondiente a la cámara de reacción. Este detalle se observa en los propios restos conservados del horno, donde la pared de dicha cámara está notablemente adelgazada por debajo de la posición de las toberas, mientras que el cuerpo alto (chimenea) solo muestra un ligero vidriado térmico. Con otro tipo de material el horno no hubiera producido estas escorias y probablemente tampoco hubiera cumplido su función. Con los restos de la estructura y la composición de la escoria pudimos reconstruir un modelo de funcionamiento del que se deduce una producción por hornada de unos $24 \mathrm{~kg}$ de hierro bruto (Rovira Lloréns y Renzi 2015: 352).

\subsection{La escala de la producción}

El total de la escoria recuperada en los cortes abiertos en La Pastora durante la campaña de 2011 asciende a $170 \mathrm{~kg}$ que, teniendo en cuenta los $37,4 \mathrm{~m}^{2}$ totales de excavación, suponen una media de $4,54 \mathrm{~kg} / \mathrm{m}^{2}$. Proyectándolos sobre las 0,6 ha en que se ha estimado grosso modo la superficie de la explotación antigua, arroja una cifra ligeramente superior a $27 \mathrm{tm}$ de escoria de 
sangrado, que equivaldrían, según el modelo propuesto, a unas $50 \mathrm{tm}$ de hierro (Rovira Lloréns y Renzi 2015: 352).

Es importante no perder de vista que estamos manejando un modelo teórico basado en las relaciones estequiométricas que proporcionan los materiales analizados, lo cual presupone aceptar que los materiales presentes en la carga reaccionan en su totalidad. Esto raramente sucede en los hornos antiguos, en los que una parte del mineral no reacciona para formar la lupia como muestra gráficamente la figura 12, correspondiente al momento de extracción de dicha lupia en un horno experimental.

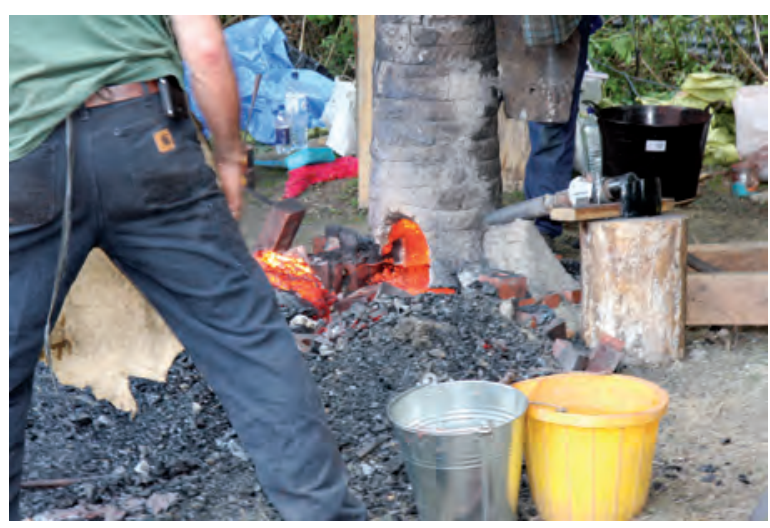

Fig. 12. Reducción experimental de mineral de hierro en un horno de chimenea ventilado con una tobera. Extracción de la lupia. Obsérvese la importante cantidad de material (carbones, mineral, escoria) extraído del horno junto con la lupia. Experimento realizado en West Dean College, Chichester (Inglaterra) en 2010, durante un encuentro de Arqueometalurgia experimental (en color en la edición electrónica).

Por la boca puede verse que queda en el interior mineral sin reaccionar, aparte del que ya se ve fuera del horno. Es decir, es un modelo de máximos. Pero no es arbitrario y las cifras que propone son un tope objetivo para poder hacer estimaciones de la producción basadas en algo más que la simple especulación subjetiva.

En todo caso, la arqueometalurgia experimental produce resultados muy variables por lo que respecta a rendimiento y otras valoraciones (Gallego Cañamero 2014a: 49). A pesar del mucho trabajo realizado en ese sentido, todavía estamos lejos de poder equiparar un experimento a datos concretos arqueológicos. En nuestro caso, la ratificación del modelo debería comprobarse experimentalmente reproduciendo el horno de La Pastora con iguales materiales constructivos, cargarlo con la cantidad de mineral que propone el modelo, analizar las escorias resultantes (que han de coincidir con las arqueológicas) y la cantidad de hierro producido.

Contrariamente a la variabilidad experimental, la homogeneidad de las escorias del entorno de $\mathrm{La}$ Pastora indica que el proceso tecnológico estaba claramente definido y se repitió sistemáticamente con resultados similares muchas veces.

Estudios experimentales recientes, refrendando la opinión de otros previos, defienden la preferencia por el uso de hornos de reducción con el sistema de tiro natural o libre -frente a los de ventilación asistida mediante fuelles- en contextos de producción intensiva (Gallego Cañamero 2014a: 42, 47-51 y 54, 2014b: 52). Aunque la discusión en torno al tema sigue abierta (véase, p. ej., alguno de los trabajos publicados en Dungworth y Doonan 2013), los paralelos etnográficos apoyan la idea de que los hornos bajos de gran talla operan por el sistema de tiro natural aprovechando el efecto chimenea, mientras que los pequeños (diámetro de la cámara de unos $50 \mathrm{~cm}$ o inferiores) se adecúan mejor a la ventilación asistida con fuelles. Sobre las limitaciones del efecto de una tobera que, a su vez, limita el diámetro eficaz de la cámara, véase Rovira Lloréns y Renzi (2010: 9192). El horno de La Pastora, por las dimensiones y el posicionamiento de sus toberas, pertenecería muy probablemente al segundo grupo.

\section{LA PASTORA Y LOS HORNOS DE REDUCCIÓN DIRECTA EN LA PENÍNSULA IBÉRICA}

Hasta donde conocemos, no son muchos los hornos de reducción directa de hierro con un nivel de conservación aceptable para sugerir como paralelos, a grandes rasgos, del horno de Aliseda. Descartadas las estructuras fenicias y orientalizantes de Toscanos, Morro de Mezquitilla, Cerro del Villar, La Fonteta, Carmona, etc., por los motivos indicados al comienzo de este trabajo, solo cabe recurrir a ámbitos geográficos más alejados, que suelen albergar además los escasos 
restos utilizados a menudo para recrear el aspecto y funcionamiento de los hornos protohistóricos y romanos más antiguos. El gran problema es que la mayoría perdieron su alzado aéreo, de forma que a menudo solo contamos con las cubetas o subestructuras excavadas en el nivel geológico de los mismos que han conllevado su valoración preferente como hornos con fosa para escorias (slag pit furnace). Tal es el caso del más antiguo de los recuperados en Les Guàrdes (El Vendrell, Tarragona) (UE7438), tal vez un horno de este tipo con pozo para escorias de $0,65 \mathrm{~m}$ de diámetro interno, fechado en el siglo IV a.C., o del más reciente (UE7235), con apenas el fondo de una cubeta alargada y escasos restos de la pared fornaria de finales del siglo III o comienzos del siglo II a.C. (Morer y Rego 1997, 2003). Ambos son modelos para la arqueología experimental (Gallego Cañamero 2014a: 39-41). Otro tanto podría decirse sobre los restos catalanes de los siglos IV-III a.C. del Puig de Sant Andreu, Ca N'Olivé y Torre dels Encantats, este último con escorias de sangrado (Rovira Hortalà 2012), u otros excavados en diferentes yacimientos ibéricos levantinos. Tampoco cabe olvidar la estructura circular de fuego de Els Vilars d'Arbeca, fechada hacia el 700 a.C., también con morfología en cubeta, aunque sin escorias que certifiquen a las claras su funcionalidad (Rovira Lloréns 2000: 215).

A esa misma modalidad, aunque en contexto celtibérico, se adscriben los restos de Segeda I (Mara, Zaragoza): un horno del que se documentó el pozo de escoria (de unos $0,45 \mathrm{~m}$ de diámetro) y el arranque del cuerpo (Rovira et al. 2012). A ellos han venido a sumarse los de La Juncada (Peracense), en plena Sierra Menera turolense (Fabre et al. 2012; Villargordo Ros et al. 2014), cuya tipología, sin embargo, constituye el mejor referente comparativo para el que ahora damos a conocer. Son tres hornos de sangrado, también denominados "hornos galo-romanos" (Gener Moret 2010: 214-215), fechados por radiocarbono entre finales del siglo $\mathrm{V}$ y el siglo III a.C., dada la práctica ausencia de material cerámico susceptible de valorarse tipológicamente (Villargordo Ros et al. 2014: 88). Como el de La Pastora, destacan por su buena conservación. Todos son de planta oval o circular. Dispusieron de un armazón estructural relativamente inalterable, elaborado mediante hiladas de lajas de arenisca y cuarcitas de pequeñas dimensiones trabadas con barro y colocadas desde la base del horno que se elevaban en altura hasta culminar en la chimenea. Sus dimensiones -tampoco muy alejadas de las del horno mejor conservado de Aliseda- serían de $0,50 \mathrm{~m}$ de diámetro interior, alcanzando la parte baja conservada del horno, parcialmente excavada en la cantera caliza de la Sierra Menera, una altura máxima de 0,40-0,50 m. Las seis hiladas conservadas del armazón del horno más completo de La Juncada serían recubiertas posteriormente con manteados de barro interiores. Finalmente, sus dos toberas, con una inclinación estimada de $130^{\circ}$, tendrían diámetros también ligeramente superiores, de 4-4,5 cm (Fabre et al. 2012: 58), si bien, atendiendo a los ensayos experimentales, se cuestiona el uso de fuelles (Villargordo Ros et al. 2014: 86). Como sucediera con los de Aliseda, los hornos fueron sometidos a los periódicos destrozos y reelaboraciones propios de su uso reiterado, aun reconociéndoles sus excavadores un nivel de reutilización muy superior al de los hornos con pozo de escoria (Villargordo Ros et al. 2014: 84-85).

Estas evidencias, en suma, refrendan el interés del horno de reducción de La Pastora. Junto con las ya mencionadas escorias de Tell Hammeh en el otro extremo del Mediterráneo amplían también el horizonte cronológico y cultural de los hornos de sangrado y, en general, la muestra disponible para la discusión en torno a los hornos de reducción directa en la protohistoria de la Península Ibérica.

\section{BIBLIOGRAFÍA}

Almagro Gorbea, M. 1977: El Bronce Final y el Período Orientalizante en Extremadura. Bibliotheca Praehistorica Hispana XIV, CSIC. Madrid.

Almagro Gorbea, M. 1993: "La introducción del hiero en la Península Ibérica. Contactos precoloniales en el Período Protoorientalizante". Complutum 4: 81-94.

Bachmann, H. G. 1982: The identification of slags from archaeological sites. Institute of Archaeology. Londres.

Blanco, E.; Cuadrado, C. y Morales, R. 2000: "Plantas en la cultura material de Fuenlabrada de Los Montes (Extremadura, España)". Anales del Jardín Botánico de Madrid 58 (1): 145-162.

Camino Mayor, J. y Villa Valdés, Á 2014: “El hierro en el registro arqueológico de la protohistoria cantábrica". I Coloquio de Arqueología Experimental 
del Hierro y Paleosiderurgia. Kobie Serie Anejo 13. Diputación Foral de Bizkaia. Bilbao: 59-74.

Carrión Marco, Y. 2004: "Usos da madeira e paleovegetação. Estudo antracológico de Alcalar 7. En E. Morán y R. Parreira (ed.): Alcalar 7. Estudo e reabilitação de un monumento megalítico. Cadernos do IPPAR II, 5. Instituto Português do Património Arquitectónico. Lisboa: 149-172.

Carrión Marco, Y. 2005: La vegetación mediterránea y atlántica de la Península Ibérica. Nuevas secuencias antracológicas. Servicio de Investigación Prehistórica, Serie de Trabajos Varios 104, Diputación Provincial de Valencia. Valencia.

Carrión Marco, Y. y Badal García, E. 2005: "Estudio antracológico de tres monumentos funerarios del Valle de Ambrona". En M. A. Rojo Guerra, M. Kunst, R. Garrido Pena, I. García Martínez de Lagrán y G. Morán Dauchez (eds.): Un desafio a la eternidad: Tumbas monumentales del Valle de Ambrona. Arqueología en Castilla y León 14, Memorias. Valladolid: 279-288.

Domergue, C. 1987: Catalogue des mines et des fonderies antiques de la Péninsule Ibérique. Publications de la Casa de Velázquez, Archéologie VIII. De Boccard. París.

Dungworth, D. y Doonan, C. P. 2013: Accidental and experimental archaeometallurgy. Historical Metallurgy Society. Londres.

Duque Espino, D. M. 2004: La gestión del paisaje vegetal en la Prehistoria Reciente y Protohistoria en la Cuenca Media del Guadiana a partir de la Antracología. Tesis Doctoral. Servicio de Publicaciones de la Universidad de Extremadura. Cáceres.

Duque Espino, D. M. 2011: "Protohistoric Anthracology in the middle valley of Rivers Guadiana and Tajo (Extremadura, Spain)". $5^{\text {th }}$ International Meeting of Charcoal analysis. The Charcoal as cultural and biological heritage. Saguntum Extra-11, Universitat de València. València: 177-178.

Duque Espino, D. M. 2015: “Antracología de Las Cortinas". En A. Rodríguez Díaz, I. Pavón Soldevila y D. M. Duque Espino (eds.): El Tiempo del Tesoro de Aliseda, II. Aproximación a su contexto arqueológico. Tagus, Asociación para el Desarrollo Integral Tajo-Salor-Almonte. Cáceres: 279-300.

Enríquez Navascués, J. J.; Rodríguez Díaz, A. y Pavón Soldevila, I. 2001: El Risco. Excavación de urgencia en Sierra de Fuentes (Cáceres). 1991 y 1993. Memorias de Arqueología Extremeña 4, Consejería de Cultura de la Junta de Extremadura. Mérida.

Fabre, J. M.; Polo, C.;Rico, Ch.; Villargordo, C. y Coustures, M. P. 2012: "Minería y siderurgia antigua en Sierra Menera (Teruel)". En A. Orejas y Ch. Rico (eds.): Minería y metalurgia antiguas. Visiones y revisiones. Homenaje a Claude Domergue. Collection de la Casa de Velázquez 128: 43-62.

FAO. 1983: Métodos simples para fabricar carbón vegetal. Estudio FAO: Montes 41. http://www.fao.
org/docrep/X5328S/X5328S00.htm (consultada el 15-7-2016)

Galán Cela, P.; Gamarra Gamarra, R. y García Viñas, J.I. 1998: Árboles y arbustos de la Península Ibérica e Islas Baleares. Ediciones Jaguar. Madrid.

Gallego Cañamero, J. M. 2013: "La siderurgia en el mundo ibérico. Primeros datos a partir de la experimentación arqueológica”. En A. Palomo, R. Piqué y X. Terradas (eds.): Experimentación en Arqueología. Estudio y difusión del pasado. Sèrie Monogràfica del Museu d'Arqueologia de Catalunya. Girona: 349-356.

Gallego Cañamero, J. M. 2014a: "Experimentando con armas ibéricas de hierro. La producción del metal en hornos de "tiro natural"”. Gladius XXXIV: 37-64.

Gallego Cañamero, J. M. 2014b: "La producción de hierro entre los pueblos ibéricos septentrionales. Experimentaciones y primeros resultados". I Coloquio de Arqueología Experimental del Hierro y Paleosiderurgia. Kobie Serie Anejo 13. Diputación Foral de Bizkaia. Bilbao: 39-58.

Gener Moret, M. 2010: "Tecnología de la metalurgia del hierro". En I. Montero Ruiz (ed.): Manual de Arqueometalurgia. Museo Arqueológico Regional de la Comunidad de Madrid. Alcalá de Henares: 187-232.

Gómez Ramos, P. 1996: “Análisis de escorias férreas: nuevas aportaciones al conocimiento de la siderurgia prerromana en España". Trabajos de Prehistoria 53(2): 145-155.

Grau Almero, E. 1999: "Antracología de la Sierra del Aljibe (Aliseda, Cáceres)". En A. Rodríguez Díaz e I. Pavón Soldevila (eds.): El poblado protohistórico de Aliseda (Cáceres). Campaña de 1995. Consejería de Cultura de la Junta de Extremadura y Ayuntamiento de Aliseda. Mérida-Aliseda: 197-202.

Grau Almero, E.; Pérez Jordà, G. y Hernández Carretero, A.M. 1998: "Paisaje yagricultura en la Protohistoria extremeña”. En A. Rodríguez Díaz (ed.): Extremadura Protohistórica: paleoambiente, economía y poblamiento. Universidad de Extremadura. Cáceres: 31-62.

Izco, J.; Amigo, J.; Ramil-Rego, P.; Díaz, R. y Sánchez, J. M. 2006: "Brezales: biodiversidad, usos y conservación”. Recursos Rurais 2: 5-24.

Liberal Muñoz, A. V. 2007: "La Mina Pastora". Revista Informativa Cancho La Plata: 10.

López González, G. 2001: Los árboles y arbustos de la Península Ibérica e Islas Baleares (especies silvestres y las principales cultivadas). Ediciones Mundi-Prensa. Madrid.

Marcos Martín, F. 1989: El carbón vegetal: propiedades y obtención. Ediciones Mundi-Prensa. Madrid.

Marguerie, D.; Bernard, V.; Bégin, Y. y Terral, J. F. 2010: "Dendroanthracologie". En S. Payette y L. Filion (eds.): La Dendroécologie. Principes, méthodes et applications. Presses de la Université Labal. Québec: 311-347. 
Morer J. y Rigo, A. 1999: Ferro i ferrers en el món ibèric. El poblat de Les Guàrdies (El Vendrell). Ed. Autopistes de Catalunya. Barcelona.

Morer J. y Rigo, A. 2003: "Les Guàrdies (El Vendrell, Baix Penedès). Un assentament metal.lúrgic d'època ibérica". Actes del Simposi Internacional d'Arqueologia del Baix Penedès 'Territoris antics a la Mediterrània i a la Cossetània oriental' (Vendrell 2001): 327-338. Barcelona.

Ortí Belmonte, M. Á. 1921: "El tesoro fenicio de Aliseda". Revista Ibérica XVI-397, 15 de octubre: 210-212.

Ortí Belmonte, M. Á. 1924: "Los fenicios y el Tesoro de Aliseda". Boletín de la Real Academia de las Ciencias y Bellas Letras y Nobles Artes de Córdoba. Año III-enero-marzo, 7: 87-98.

Pascual Mayoral, P. y García Ruiz, P. 2007: “Aprovechamientos del brezo en Moncalvillo (La Rioja)". Altza, hautsa kenduz IX: 103-111.

Pavón Soldevila, I.; Rodríguez Díaz, A. y Duque Espino, D. M. 2015: "El poblado de la Sierra del Aljibe y su territorio: secuencia, recursos mineros y poblamiento rural". En A. Rodríguez, I. Pavón y D. M. Duque (eds.): El tiempo del tesoro de Aliseda, II. Aproximación a su contexto arqueológico. Tagus, Asociación para el Desarrollo Integral Tajo-SalorAlmonte. Cáceres: 109-177.

Ramos Santos, J. M. 2006: "La transformación del paisaje vegetal y los aprovechamientos forestales tradicionales en la Sierra de la Culebra (Zamora)". Investigaciones Geográficas 40: 55-72.

Rebollada Casado, E.; Arias, M. y Gumiel, P. 2010: "Mina Pastora (Aliseda, Cáceres): contribución al desarrollo del patrimonio geológico-minero de Extremadura". En E. Romero Macías (ed.): Patrimonio geológico y minero. Una apuesta por el desarrollo local sostenible. Ediciones de la Universidad de Huelva. Huelva: 249-254.

Renzi, M. y Rovira Lloréns, S. 2009: "Slags of early iron production in the Iberian Peninsula". En J. F. Moreau, R. Auger, J. Chabot y A Herzog (eds.): Proceedings of the $36^{\text {th }}$ International Symposium of Archaeometry (Quebec 2006). Cahiers d'Archéologie du CELAT, Série Archéometrie 7. Quebec: 399-406.

Renzi, M.; Rovira, S.; Rovira, M. C. y Montero, I. 2013: "Questioning research of early iron in the Mediterranean". En J. Humphris y Th. Rehren (eds.): The World of Iron. Ed. Archetipo Publications. Londres: 178-187.

Rodríguez Díaz, A.; Ortiz Romero, P.; Pavón Soldevila, I. y Duque Espino, D. M. 2014: El Tiempo del Tesoro de Aliseda, I. Historia e historiografía del hallazgo. Tagus, Asociación para el Desarrollo Integral Tajo-Salor-Almonte. Cáceres.

Rodríguez Díaz, A. y Pavón Soldevila, I. 1999: El poblado protohistórico de Aliseda (Cáceres). Campaña de 1995. Consejería de Cultura de la Junta de Extremadura y Ayuntamiento de Aliseda. Mérida-Aliseda.
Rodríguez Díaz, A.; Pavón Soldevila, I. y Duque Espino, D. M. (eds.) 2015: El tiempo del tesoro de Aliseda, II. Aproximación a su contexto arqueológico. Tagus, Asociación para el Desarrollo Integral Tajo-Salor-Almonte. Cáceres.

Rodríguez Díaz, A.; Pavón Soldevila, I.; Duque Espino, D. M.; Ponce de León Iglesias, M.; Hunt Ortiz, M. A. y Merideth, C. 2013: "La explotación tartésica de la casiterita entre los ríos Tajo y Guadiana: San Cristóbal de Logrosán (Cáceres)". Trabajos de Prehistoria 70 (1): 95-113.

Rovira Hortalà, M. C. 2012: “La producció siderúrgica en Època Ibèrica a Catalunya". Boscos de Ferro. Actes de les primeres jornades de recerca $i$ desenvolupament de la Vall Ferrera (Alins 2012): 41-50. Tremp.

Rovira Lloréns, S. 2000: “Continuismo e innovación en la metalurgia ibérica”. En C. Mata y G. Pérez Jordà (eds.): Ibers. Agricultors, artesans $i$ comerciants. III Reunió sobre Economia en el Món Ibèric. Saguntum Extra 3, Universitat de València. València: 209-221.

Rovira Lloréns, S. y Burillo Mozota, F. 2005: “Experimentos de fundición de minerales de hierro en la ciudad-estado celtibérica de Segeda (Mara, Zaragoza). En J. Molera; J. Farjas; P. Roura y T. Pradell (eds.): Avances en Arqueometría 2005. Actas del VI Congreso Ibérico de Arqueometría (Girona 2005): 137-144. Girona

Rovira, S.; Burillo, F.; López, R. e Ibáñez, J. 2012: "Metalurgia y explotación de los recursos minerales en el entorno de la ciudad-estado celtibérica de Segeda I (Mara, Zaragoza)". En A. Orejas y C. Rico (eds.): Minería y metalurgia antiguas. Visiones y revisiones. Casa de Velázquez. Madrid: 27-42.

Rovira Lloréns, S. y Gómez Ramos, P. 1999: “Arqueometalurgia del hierro de época orientalizante y tardo-republicana en Aliseda (Cáceres)". En A. Rodríguez Díaz e I. Pavón Soldevila (eds.): El poblado protohistórico de Aliseda (Cáceres). Campaña de 1995. Consejería de Cultura de la Junta de Extremadura y Ayuntamiento de Aliseda. MéridaAliseda: 220-233.

Rovira Lloréns, S. y Renzi, M. 2010: “Las operaciones pirometalúrgicas y sus subproductos". En I. Montero Ruiz (ed.): Manual de Arqueometalurgia. Museo Arqueológico Regional de la Comunidad de Madrid. Alcalá de Henares: 87-122.

Rovira Lloréns, S. y Renzi, M. 2015: “Caracterización arqueométrica de las escorias de hierro de la mina 'La Pastora"'. En A. Rodríguez, I. Pavón y D. M. Duque (eds.): El Tiempo del Tesoro de Aliseda, II. Aproximación a su contexto arqueológico. Tagus, Asociación para el Desarrollo Integral Tajo-SalorAlmonte. Cáceres: 343-352.

Severin, T.; Rehren, Th. y Schleicher, H. 2011: "Early metal smelting in Ethiopia: copper or iron?". European Journal of Mineralogy 23: 981-992. 
Théry-Parisot, I. 2001: L'économie des combustibles au Paléolithique. CEPAM, Dossiers de documentation archéologique 20. CNRS éditions. Paris.

Veldhuijzen, H. A. y Rehren, Th. 2007: "Slags and the City. Early iron production at Tel Hammeh, Jordan, and Tel Beth-Shemesh, Israel". En S. La Niece, D. R. Hook y P. T. Craddock (eds.): Metals and Mines: studies in Archaeometallurgy. Ed. Archetype. Londres: 189-201.

Vilaça, R. 2006: “Artefactos de hierro em contextos do Bronze Final do territorio portugês: novos contributos e revaliaçao dos dados". Complutum 17: 81-101.

Vilaça, R. 2013: "L'arrivée des premiers fers dans l'Occident atlantique". Les transferts de technologie au premier millénaire av. J.-C. dans le sud-ouest de
1'Europe. Mélanges de la Casa de Velázquez Nouvelle série 43-1: 39-64.

Villargordo Ros, C.; Pol Cutando, C.; Fabre, J. M.; Coustures, M. P. y Rico, Ch. 2014: "Innovación sin desarrollo: el taller metalúrgico de La Juncada (Peracense, Teruel). Evidencias de la producción de hierro en los siglos IV-III a.C. en el ámbito celtibérico del área minera de Sierra Menera". I Coloquio de Arqueología Experimental del Hierro y Paleosiderurgia. Kobie Serie Anejo 13. Diputación Foral de Bizkaia. Bilbao: 75-92.

Wolf. F. y Vogel, E. 1985: Manual para la producción de carbón vegetal con métodos simples. Reporte Científico 2, Universidad Autónoma de Nuevo León. México. 